\title{
A Eleição de Dilma em 2010 e seus Determinantes: Evidências Empíricas do Programa Bolsa Familia
}

\section{The 2010 Dilma's Election and lts Determinants: Empirical Evidence of the Bolsa Famlia Program}

\author{
Ana Elisa Gonçalves Pereira* \\ Cláudio Shikida** \\ Felipe Garcia Ribeiro* ** \\ Luciano Nakabashi****
}

\begin{abstract}
Resumo: O presente artigo apresenta evidências empíricas de que o Programa Bolsa Família teve um papel preponderante na eleição da candidata do Partido dos Trabalhadores, Dilma Rousseff, em 2010, e que esse efeito foi superior ao do desempenho econômico favorável nos dois mandatos do governo Lula. Utilizando dados agregados por município, os resultados, sob o modelo de regressão beta, mostram que esse cenário se mantém mesmo quando se leva em conta outras variáveis de cunho econômico, social e político e as especificidades regionais não observáveis. As estimativas obtidas apontam também para uma votação mais expressiva em Dilma nos municípios com menor nível de escolaridade, dando suporte à hipótese presente na literatura de que essas populações tendem a ser mais dependentes do Estado e, portanto, a primar pela manutenção do poder vigente. Os resultados obtidos são robustos a diferentes especificações.
\end{abstract}

Palavras-chave: Eleições presidenciais. Bolsa família. Regressão beta.

Abstract: This paper presents empirical evidence that the Bolsa Familia cash transfer program played a major role in the election of Dilma Rousseff, the Workers' Party candidate, in 2010 presidential election. Our analysis indicates that this effect was more relevant than the impact of the favorable economic scene during the two Lula's mandates. Employing a sample of 5.564 Brazilian municipalities, the results obtained from Beta Regression models point out that this statement holds even when we take into account other economic, social and political variables, as well as unobservable regional

* $\quad$ Doutoranda em Economia pela Escola de Economia de São Paulo da Fundação Getúlio Vargas (EESP-FGV). Pesquisadora visitante na Universidade da Pensilvânia. E-mail: anaelisagpereira@ gmail.com

** Doutor em Economia pela Universidade Federal do Rio Grande do Sul (UFRGS). Professor adjunto do Ibmec-MG. Professor colaborador do Programa de Pós-Graduação em Organizações e Mercados (PPGOM) da Universidade Federal de Pelotas (UFPel). E-mail: cdshikida@gmail.com

*** Doutor em Economia pela Escola de Economia de São Paulo da Fundação Getúlio Vargas (EESPFGV). Professor do do Programa de Pós-Graduação em Organizações e Mercados (PPGOM) da Universidade Federal de Pelotas (UFPel). E-mail: felipe.garcia.rs@gmail.com

**** Doutor em Economia pela Universidade Federal de Minas Gerais (UFMG). Professor do Departamento de Economia da Faculdade de Economia, Administração e Contabilidade de Ribeirão Preto (FEA-RP) da Universidade de São Paulo (USP). Pesquisador do CNPq. E-mail: luciano.nakabashi@gmail.com. O autor agradece o auxílio financeiro do CNPq. 
characteristics. The empirical results also point to a greater vote share to Dilma in the municipalities that show lower levels of schooling, giving support to the literature that proposes that less educated people tend to be more dependent on the Government and, therefore, they tend to keep the status quo unchanged. Different specifications confirm the results obtained.

Keywords: Presidential election. Bolsa família. Beta regression.

JEL Classification: H53; I38; J18.

\section{Introdução}

Os elementos que determinam o sucesso de um candidato nas eleições presidenciais são analisados com muita atenção pelos membros de sua equipe e pelos integrantes dos seus respectivos partidos políticos, pois eles desejam maximizar as chances de sucesso eleitoral. No entanto, esse é um tema de interesse mais amplo, pois envolve interação entre agentes econômicos, sociais e políticos, e os resultados desse processo geram efeitos relevantes em toda a trajetória de desenvolvimento de uma nação. Essas interações e seus efeitos são foco de estudo de cientistas políticos e sociais, além de despertar um interesse cada vez maior por parte de pesquisadores que utilizam ferramentais provenientes das ciências econômicas.

Os elementos que definem os resultados de uma eleição mudam consideravelmente dependendo do país, do momento histórico, das condições sociais, econômicas, políticas e dos candidatos que pretendem ocupar o cargo. No Brasil, essa disputa vem se polarizando, nas últimas duas décadas, em torno de dois partidos políticos: Partido dos Trabalhadores (PT) e Partido da Social Democracia Brasileira (PSDB). Nas últimas eleições presidenciais, ocorreram transformações relevantes no eleitorado que determinou a escolha do presidente, sobretudo entre 2002 e 2006. No pleito que levou à reeleição de Luiz Inácio Lula da Silva, a maior parcela dos votos foi obtida nas regiões menos desenvolvidas do Brasil, ao contrário de 2002.

Em 2010, a candidata Dilma Rousseff, que no início de sua campanha apresentou intenção de voto pouco expressiva nas pesquisas eleitorais, ganhou força, levou a disputa para o segundo turno e venceu. Esse resultado foi fortemente atribuído, pela mídia, ao apoio irrestrito do então presidente Lula - que terminou o seu segundo mandato com elevado índice de aprovação ${ }^{1}$-, ao razoável crescimento econômico apresentado em seus oito anos de governo e à difusão do Programa Bolsa Família (PBF) durante a última gestão.

No entanto, será que o cenário traçado encontra suporte nos dados empíricos? O padrão de votação no território nacional em 2010 se assemelha àquele das eleições de $2006 ?^{2}$ O foco nesses dois períodos foi pelo fato de outros estu-

1 Ferreira, Sakurai e Oliveira (2011) sugerem que fatores econômicos foram elementos essenciais na determinação dos elevados índices de aprovação no governo Lula.

2 Por padrão de votação, consideram-se as semelhanças ou diferenças em algumas características 
dos já terem coberto as eleições anteriores, sendo que eles servem de base de comparação para os resultados encontrados na presente análise. Adicionalmente, pela evolução de programas de transferências de renda que ocorreu, sobretudo, a partir do primeiro mandado do governo Lula, é razoável considerar que essa é uma variável comum que afetou a proporção de votos nos candidatos do PT nas duas ocasiões.

No presente estudo, ao notar que o perfil do eleitorado petista em 2010 se assemelha ao de 2006, e não ao de 2002, busca-se investigar qual das hipóteses apontadas anteriormente se ajusta melhor aos dados municipais. Em outras palavras, objetiva-se averiguar quais aspectos foram mais relevantes na determinação da fração de votos em Dilma nos municípios, em 2010, com foco no crescimento da renda, no acesso da população mais carente ao PBF e no efeito Lula, sendo que este captura parte do que a literatura internacional denomina incumbent effect, além de outros fatores sociais, econômicos e políticos que também servem de controle para evitar problemas de correlação espúria por variável omitida.

Apesar da relevância, as variáveis de controle assumem um papel secundário na análise empírica realizada. Por meio do estudo desses dados, pode-se lançar luz sobre o mapa político que se configura no país e sobre quais elementos se mostraram mais relevantes diante da opinião pública, refletidos no voto e, portanto, nas eleições presidenciais de 2010. Como a variável dependente encontra-se no intervalo $(0,1)$, utiliza-se para a análise empírica o modelo de regressão beta. ${ }^{3}$

As contribuições do presente artigo ocorrem pela análise de um fenômeno pouco explorado no Brasil, ainda mais quando se considera o uso de ferramentais e elementos teóricos comumente utilizados em análises econômicas. Estudos nessa direção foram realizados com foco nos resultados de eleições anteriores. Alguns exemplos são os trabalhos de Canêdo-Pinheiro (2009), Marques et al. (2009), Zucco (2008) e Abensur, Cribari-Neto e Menezes (2007). Todos estes estudos servem de base de comparação para os resultados encontrados na presente análise, até mesmo para se identificar as alterações que ocorrem nos processos eleitorais ao longo do tempo.

Outras importantes contribuições são a metodologia de estimação - que, embora já tenha sido empregada, são poucos os estudos que a utilizam e que têm como unidade de análise o caso brasileiro -, a separação dos efeitos do PBF em duas partes, que permite analisar o seu alcance e o gasto per capita, além de uma análise cuidadosa com a inclusão de variáveis de controle que capturam a

dos eleitores na média de cada município, como escolaridade, grau de urbanização, nível do IDH, região do país, etnia, entre outros. Em outras palavras, se o perfil do eleitorado de Lula em 2006 é semelhante ao de Dilma em 2010, considerando as características médias de cada município brasileiro.

3 Dentre os artigos citados na revisão da literatura, apenas o de Abensur, Cribari-Neto e Menezes (2007) utiliza esse método. Para uma boa resenha sobre o tema, ver Cribari-Neto e Zeileis (2010). 
prevalência e incidência da pobreza nos municípios brasileiros, além de variáveis políticas, econômicas e sociais. Com a adição de vários controles, os resultados encontrados são mais confiáveis. Ao analisar o efeito Lula, que captura parte do incumbent effect, existe uma diferenciação em relação aos estudos anteriores por não ser um processo de reeleição. No entanto, as evidências sugerem que esse efeito esteve presente de forma decisiva.

Há uma vasta literatura na área da Ciência Política que busca identificar os determinantes de eleições, e, nos últimos anos, um dos pontos mais destacados e investigados nessa literatura é o incumbent effect sobre desempenho eleitoral (ver, por exemplo, Ansolabehere e Snyder (2000, 2004), Ansolabehere, Snyder e Stewart (2000) e Uppal $(2009,2010)$. Esse efeito trata da vantagem que o incumbente possui sobre os demais participantes no processo eleitoral. Embora Dilma estivesse, em 2010, disputando pela primeira vez a presidência da República, ela foi a candidata que representava a situação. Neste caso específico, uma das possíveis vantagens do incumbente no processo eleitoral de 2010 foi a implantação de alguns programas sociais e, sobretudo, a sua ampliação. Portanto, este artigo também contribui com uma investigação do papel desses programas sociais de transferência de renda sobre o desempenho do político (ou partido) incumbente na disputa eleitoral.

Dessa forma, pode-se dizer que o presente artigo tenta identificar um dos possíveis canais que deixa o político/partido incumbente em vantagem em relação aos demais candidatos: os programas de transferência de rendas. Outros canais não analisados são capturados pelo efeito Lula, ou seja, a relação existente entre a proporção de votos que Lula obteve em cada município, em 2006, e aquela obtida por Dilma, em 2010. Para os Estados Unidos, vários outros canais são investigados na literatura, como a prevalência de votos e os gastos em campanha. Para um país em desenvolvimento como o Brasil, acredita-se que programas sociais implantados pelo incumbente possam explicar parte do seu sucesso em eleições subsequentes. ${ }^{4}$

A análise econométrica realizada aponta para a predominância do efeito do alcance do PBF sobre o efeito do crescimento da renda per capita na explicação da proporção de votos obtidos por Dilma nos municípios. Os resultados indicam um efeito positivo e significativo desse programa de transferência de renda sobre a fração de votos de Dilma, no dia 31 de outubro de 2010, enquanto o crescimento do PIB per capita durante a "era Lula" não se mostrou significativo, controlando para outras variáveis sociais, econômicas e políticas.

$4 \quad$ Apesar de o efeito incumbente estar relacionado ao candidato que tenta a reeleição, o termo é utilizado no presente estudo porque os resultados encontrados indicam que a população via em Dilma uma continuidade das políticas econômicas e sociais de Lula, além de muitas vantagens, por ser a candidata da situação semelhante ao candidato que tenta a reeleição. 
Outro resultado importante é que, mesmo quando se controla para uma série de variáveis sociais e econômicas, a proporção de votos municipais no PT mostraram uma grande inércia entre 2006 e 2010, sendo uma evidência da importância do apoio do então presidente Lula à candidata Dilma e, portanto, da existência do incumbent effect, estando também de acordo com as evidências apresentadas por Canêdo-Pinheiro (2009) e por Zucco (2008) de que as regiões menos desenvolvidas e com menor nível de escolaridade tendem a depender mais do Estado e a prezar pela manutenção do poder nas mãos do mesmo grupo.

Mesmo quando se controla pela incidência e pela prevalência de pobreza, os efeitos estimados para o PBF sobre a proporção de votos obtidos por Dilma seguem positivos, significativos e de magnitudes próximas às observadas nas estimações sem controles para pobreza. Tal observação afasta a hipótese de que as estimações obtidas poderiam ser enviesadas em decorrência de má especificação dos modelos. Além disso, é interessante dizer que pobreza extrema, medida no ano de 2010, também exerceu efeito positivo sobre os votos realizados em Dilma, mesmo quando se controla para o efeito do PBF.

De uma forma geral, as evidências denotam que programas dessa natureza (cash transfer programs), que se difundiram na América Latina em meados de 1990, independentemente do sucesso na manutenção do crescimento econômico e na redução da pobreza e da desigualdade, foram importantes para o sucesso do PT nas urnas, mesmo controlando para o efeito Lula e para as demais variáveis de controle.

Além desta introdução, o presente artigo conta com outras cinco seções: a segunda traz uma resenha de trabalhos teóricos e empíricos que abordam a relação entre desempenho econômico e resultados eleitorais; a terceira apresenta, além da descrição das variáveis e a origem dos dados empregados, as especificações que servem de base para a análise empírica e o método econométrico utilizado; a quarta fornece os resultados da análise empírica e sua interpretação; a quinta seção apresenta exercícios econométricos adicionais que visam checar a validade dos resultados obtidos, ou seja, a robustez dos resultados obtidos na seção anterior; e, por fim, a sexta traça as considerações finais do trabalho.

\section{Literatura Prévia: Determinantes Econômicos de Resultados Eleitorais}

O debate acerca da crescente extensão dos programas de transferência de renda durante os dois mandatos de Luiz Inácio Lula da Silva, sobretudo do $\mathrm{PBF},{ }^{5}$

5 Segundo o Ministério de Desenvolvimento Social (MDS), o Bolsa Família é um programa de transferência direta de renda com condicionalidades, que beneficia famílias em situação de pobreza e de extrema pobreza. O Programa integra o Fome Zero, que tem como objetivo assegurar o direito humano à alimentação adequada. Contemplava em 2010 mais de 12 milhões de famílias com renda familiar de até $\mathrm{R} \$ 140$ por pessoa. A renda, o número e a idade dos filhos determinam 
e o desempenho eleitoral do PT nas últimas eleições presidenciais tornaram-se foco de debate acadêmico nos últimos anos. Essa literatura, ainda incipiente, tem buscado precisar os fatores socioeconômicos mais relevantes empiricamente na determinação da parcela de votos dos presidenciáveis. Com especial enfoque nos programas do tipo cash transfer, alguns economistas e cientistas políticos têm encontrado, em bases de dados brasileiros municipais ou estaduais, um campo fértil para mensurar possíveis determinantes dos resultados eleitorais das últimas décadas.

De acordo com essa literatura, pode-se verificar uma reversão no padrão de votação em 2006 em relação à eleição anterior: o perfil do eleitorado de Lula se modifica substancialmente (HUNTER; POWER, 2007; SHIKIDA et al., 2009; CANÊDO-PINHEIRO, 2009). Enquanto, em 2002, Lula apresentou uma votação mais expressiva nas regiões mais desenvolvidas do país, mais urbanizadas, com renda mais elevada e maior nível de escolaridade, em 2006 foram os municípios menos desenvolvidos e mais dependentes do Estado que apresentaram uma fração de votos maior em Lula.

Esse cenário tem sido atribuído a fatores distintos na literatura. Hunter e Power (2007) apontam três prováveis explicações para tal padrão eleitoral, sendo que elas não são excludentes. Uma possibilidade é que as populações mais carentes, com menor nível educacional e menor acesso à informação não tiveram amplo acesso aos escândalos de corrupção do primeiro mandato de Lula ou não deram um peso relevante a tais escândalos no momento de escolher o voto. Uma segunda explicação levantada é a percepção de melhora nas condições de vida das classes menos favorecidas, durante os anos de 2002 a 2006, traduzida em gratidão à política de Lula e do PT (hipótese esta defendida pelos autores). Separando em decis de renda, Ellery et al. (2013), de fato, mostram que as famílias pertencentes aos menores decis de renda foram aquelas que apresentaram taxas de crescimento da renda mais elevadas. A terceira possibilidade é que esses votos sejam reflexos da massificação de programas de transferência de renda como o PBF.

Canêdo-Pinheiro (2009) faz uso desse terceiro argumento. O autor evidencia um impacto significativo da extensão do PBF sobre os votos obtidos por Lula, em 2006, nos municípios brasileiros, sendo muito superior ao efeito do desempenho econômico favorável. Em municípios com renda per capita menor, mais famílias em situação de pobreza ou extrema pobreza - ou seja, aquelas que têm maior parcela de sua população contemplada por programas de transferência direta de renda - apostaram, por meio do voto, na continuidade do PT no poder para garantir a manutenção dos benefícios provenientes desses programas. Além disso, Canêdo-Pinheiro (2009) ressalta a hipótese de Zucco (2008) de que as regiões

o valor do benefício, que antes do reajuste de março de 2011 , variava entre $R \$ 22$ e $R \$ 200$ reais. 
menos desenvolvidas e com menor nível de escolaridade tendem a depender mais do Estado e a prezar pela manutenção do poder nas mãos do mesmo grupo.

Zucco (2008) identifica uma regularidade nesse padrão: o candidato da situação apresentou uma performance eleitoral mais satisfatória nas regiões menos desenvolvidas em todos os turnos de todas as eleições de 1994 a 2006, independentemente do partido, das propostas e da ideologia desse candidato. $\mathrm{O}$ autor aponta ainda a imensa dificuldade em se dissociar os efeitos do crescimento econômico e dos programas de transferência de renda nas regiões mais pobres. $\mathrm{O}$ autor argumenta que, em regiões carentes, pouca atividade econômica privada é desenvolvida e a percepção dos eleitores em relação à situação econômica está fortemente atada ao seu bem-estar econômico, sendo este decorrente, primordialmente, dos benefícios recebidos do governo.

Ao contrário de Canêdo-Pinheiro (2009), Marques et al. (2009) e Abensur, Cribari-Neto e Menezes (2007), o trabalho de SHIKIDA et al. (2009) contesta a relevância do PBF para a reeleição de Lula em 2006. Utilizando o método de econometria espacial, os autores encontram evidências de que o sucesso eleitoral do PT nas regiões menos desenvolvidas do país decorreu de mudanças favoráveis às populações de baixa renda no mercado de trabalho, controle inflacionário e sucesso exportador brasileiro durante o primeiro mandato de Lula. Para os autores, a votação de Lula foi mais expressiva nos municípios mais pobres - mais desiguais e com mais analfabetos -, mas sem fortes evidências de que o PBF em si tenha exercido impacto significativo sobre o resultado eleitoral.

$\mathrm{Na}$ literatura internacional, o papel do desempenho econômico na determinação de resultados eleitorais pertence à agenda de pesquisa de cientistas políticos, econômicos e sociais há muitos anos. Fair (1978) é um dos primeiros a apresentar uma estrutura teórica e econométrica para identificar o impacto da economia em eleições, em especial para a presidência dos Estados Unidos. Segundo ele, medidas econômicas, reais ou nominais parecem ter um importante papel na decisão do eleitorado nas decisões de voto para presidente. Além disso, Fair encontra evidências de que os eleitores não levam em consideração o passado político dos partidos não incumbentes, enquanto para os incumbentes apenas os eventos que ocorrem no ano eleitoral.

Mais recentemente, com dados estaduais dos Estados Unidos, Kahane (2009) avalia o efeito do ambiente econômico no padrão de votação para presidente durante o período compreendido entre 1972 e 2004. Com o método de efeitos fixos para os estados, o autor verifica que variáveis econômicas (renda, taxa de desemprego e outras) são importantes na determinação do padrão de votação para presidente nos Estados Unidos. Kahane (2009) também não encontra evidências de vantagem para o partido incumbente. 
Já em relação aos efeitos de programas de transferências de renda, não existe consenso na literatura internacional. Por exemplo, Levitt e Synder Jr. (1997), através da metodologia de variáveis instrumentais, não encontram evidências de que gastos com seguridade social e políticas de assistência social exerçam qualquer influência no resultado eleitoral nos Estados Unidos. Já Cerda e Vergara (2008), com informações municipais de três anos eleitorais para presidência do Chile (1989, 1993 e 1999), encontram evidências de que algumas políticas de transferência de renda trazem vantagens políticas, em termos de desempenho eleitoral, aos partidos incumbentes. Para o Uruguai, Manacorda, Edward e Vigorito (2010) encontram indícios de que o legado político para os partidos que implantam políticas de transferência de renda vai além do período de existência do programa.

Mais recente, De La O (2013) avalia o papel do maior programa de transferência de renda condicionada do México, o Progresa, sobre o desempenho eleitoral dos incumbentes e dos concorrentes. A autora utiliza a fase experimental do programa para a identificação da relação causal entre o programa e o desempenho político no ano de 2000. Os resultados obtidos apontam para um efeito positivo de $9 \%$ no percentual de votos obtidos pelo partido incumbente, enquanto que para a proporção de votos obtidos pelos demais partidos, os efeitos são nulos.

Posto o debate anterior, o presente artigo objetiva colaborar com a literatura que avalia o papel do desempenho econômico nos resultados eleitorais, comparando com aquela que avalia os resultados de políticas sociais nos resultados eleitorais, com especial ênfase nos programas de transferência de renda. Em outras palavras, objetiva-se averiguar quais aspectos são mais relevantes na determinação da fração de votos em Dilma nos municípios em 2010: o crescimento da renda, o acesso ao PBF, ou outros fatores sociais, econômicos e políticos.

\section{Descrição dos Dados e Metodologia}

Para a análise empírica subsequente, empregou-se a proporção de votos válidos obtidos por Dilma Rousseff no segundo turno das eleições presidenciais em 2010 como variável dependente. O alcance do PBF - definido como a proporção de famílias beneficiadas pelo programa em cada município em outubro de 2010 -, o crescimento real do PIB per capita entre 2002 (antes do primeiro mandato de Lula) e 2008, ano imediatamente anterior aos maiores efeitos da crise internacional no Brasil, a escolaridade média da população com mais de 25 anos, e outras variáveis sociais, políticas e econômicas relevantes foram incluídas na análise como variáveis explicativas. Como alternativa à variável "alcance do $\mathrm{BF}$ ”, empregou-se o valor destinado ao $\mathrm{PBF}$ dividido pela população em cada município (BF per capita). 
A justificativa para a utilização de ambas as variáveis, BF per capita e alcance do $\mathrm{BF}$, é que o valor do benefício recebido pelas famílias contempladas pelo programa pode variar entre $R \$ 22$ e $R \$ 200$, segundo o Ministério de Desenvolvimento Social. A variável de alcance do PBF leva em conta apenas a proporção de famílias que usufruem do benefício, independentemente do valor mensal recebido. Ao se empregar as duas variáveis na análise, pode-se verificar separadamente qual o efeito de se aumentar o número de famílias que recebem o benefício do valor médio recebido por cada família, fornecendo informações relevantes sobre como o programa afeta o processo eleitoral.

O emprego dessas variáveis busca captar em que medida o crescimento da economia - e consequente redução do desemprego e melhoria do padrão de consumo da população - e o referido programa de transferência de renda são capazes de explicar o diferencial na proporção de votos entre os municípios, controlando para outras variáveis, como escolaridade, prevalência de pobreza, renda domiciliar per capita, desigualdade de renda, etnia, cenário político, preferência religiosa e características regionais não observáveis.

Os dados utilizados têm como principais fontes primárias o Tribunal Superior Eleitoral (TSE), o Instituto Brasileiro de Geografia e Estatística (IBGE), o Instituto de Pesquisa Econômica Aplicada (Ipea) e a Controladoria Geral da União (CGU). O índice de desigualdade de renda de Gini foi retirado do Atlas de Desenvolvimento Humano, do Programa das Nações Unidas para o Desenvolvimento (PNUD), e dados referentes à eleição de 2006 e ao alcance do PBF foram retirados da base de Zucco (2008). A descrição das variáveis e as fontes de dados encontram-se na Tabela 1.

Tabela 1 - Descrição das variáveis utilizadas

\begin{tabular}{l|l|l}
\hline \multicolumn{1}{c|}{ Variável } & \multicolumn{1}{|c}{ Descrição } & \multicolumn{1}{|c}{ Fonte } \\
\hline Dilma 2010.2 & $\begin{array}{l}\text { Proporção dos votos válidos obtidos por Dilma } \\
\text { Rousseff no segundo turno das eleições presi- } \\
\text { denciais de 2010. }\end{array}$ & TSE $^{\mathrm{a}}$ \\
\hline Serra 2010.2 & $\begin{array}{l}\text { Proporção dos votos válidos obtidos por José } \\
\text { Serra no segundo turno das eleições presidenci- } \\
\text { ais de 2010. }\end{array}$ & TSE \\
\hline alcanceBF & $\begin{array}{l}\text { Proporção de famílias beneficiadas pelo PBF em } \\
\text { outubro de 2010. }\end{array}$ & $\begin{array}{l}\text { Zucco(2008) } \\
\text { b/MDSc }\end{array}$ \\
\hline BFpercap & $\begin{array}{l}\text { Razão entre o valor transferido às famílias pelo } \\
\text { PBF (2010) e a população (2010). }\end{array}$ & CGUde IBGE \\
\hline crescPIB & $\begin{array}{l}\text { Crescimento real do PIB per capita entre 2002 e } \\
\text { 2008. }\end{array}$ & IBGE \\
\hline PIBpercap & PIB per capita em 2008. & IBGE \\
\hline
\end{tabular}


conclusão.

\begin{tabular}{l|l|l}
\multicolumn{1}{c|}{ Variável } & \multicolumn{1}{|c}{ Descrição } & \multicolumn{1}{|c}{ Fonte } \\
\hline Rdom & Renda domiciliar per capita em 2010. & IPEA $^{\mathrm{f}}$ \\
\hline ExtPob2000 g & $\begin{array}{l}\text { Porcentagem de pessoas extremamente pobres } \\
(2000)\end{array}$ & IPEA \\
\hline ExtPob2010 h & $\begin{array}{l}\text { Porcentagem de pessoas extremamente pobres } \\
\text { (2010) }\end{array}$ & IPEA \\
\hline govPT & $\begin{array}{l}\text { Dummy que assume valor 1 se o governador } \\
\text { eleito em 2006 for do PT e 0, caso contrário. }\end{array}$ & IPEA \\
\hline prefPT & $\begin{array}{l}\text { Dummy que assume valor 1 se o prefeito eleito } \\
\text { em 2008 for do PT e 0, caso contrário. }\end{array}$ & IPEA \\
\hline pref*govPT & $\begin{array}{l}\text { Dummy que assume valor 1 se o prefeito e o } \\
\text { governador são do PT e 0, caso contrário. }\end{array}$ & IPEA \\
\hline Educ & $\begin{array}{l}\text { Anos de estudo médios da população com mais } \\
\text { de 25 anos (2000). }\end{array}$ & IPEA \\
\hline Pentecost & $\begin{array}{l}\text { Porcentagem da população de religião evan- } \\
\text { gélica de origem pentecostal. }\end{array}$ & $\begin{array}{l}\text { Zucco } \\
(2008)\end{array}$ \\
\hline Nbranco & $\begin{array}{l}\text { Participação dos que se autodeclararam não } \\
\text { brancos no Censo 2000 da população. }\end{array}$ & $\begin{array}{l}\text { Zucco } \\
(2008)\end{array}$ \\
\hline Idh2000 & $\begin{array}{l}\text { Índice de desenvolvimento humano (IDH) em } \\
\text { 2000. }\end{array}$ & IPEA \\
\hline Gini & $\begin{array}{l}\text { Índice de desigualdade de renda de Gini em } \\
\text { 2000. }\end{array}$ & Pnudi \\
\hline Lula2006.2 & $\begin{array}{l}\text { Proporção dos votos válidos obtidos por Lula } \\
\text { no segundo turno das eleições presidenciais de } \\
\text { 2006. }\end{array}$ & $\begin{array}{l}\text { Zucco } \\
(2008)\end{array}$ \\
\hline Alckmin & $\begin{array}{l}\text { Proporção dos votos válidos obtidos por Alck- } \\
\text { min no segundo turno das eleições presidenciais } \\
\text { de 2006. }\end{array}$ & $\begin{array}{l}\text { Zucco } \\
(2008)\end{array}$ \\
\hline
\end{tabular}

Fonte: Elaboração própria a partir de dados do TSE, do IBGE, do IPEA e da CGU.

Notas: ${ }^{a}$ Tribunal Superior Eleitoral; ${ }^{\text {b }}$ A base de dados do referido artigo é disponibilizada publicamente pelo autor; ${ }^{\mathrm{c}} \mathrm{A}$ fonte primária de dados é o Ministério de Desenvolvimento Social; ${ }^{\mathrm{d}}$ Controladoria Geral da União. O valor das despesas governamentais é divulgado em nível municipal no Portal da Transparência do Governo Federal. Para o cálculo do BFpercap, foi empregado o

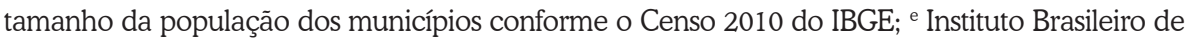
Geografia e Estatística; ${ }^{\mathrm{f}}$ Instituto de Pesquisa Econômica Aplicada; ${ }^{\mathrm{g}}$ São considerados indivíduos extremamente pobres aqueles residentes em domicílios particulares permanentes com renda domiciliar per capita igual ou inferior a $\mathrm{R} \$ 70,00$ mensais, em reais de agosto de $2010 ;{ }^{\mathrm{h}}$ Definição idêntica à da variável ExtPob2000; i Programa das Nações Unidas para o Desenvolvimento. Dados retirados do software: Atlas do Desenvolvimento Humano no Brasil. 
Na Tabela 2 estão as estatísticas descritivas das variáveis utilizadas na análise empírica. Percebe-se como o PBF atinge uma boa parte das famílias brasileiras: a média dos municípios era de 35\% das famílias, em 2010, chegando a mais de $90 \%$, em alguns deles. No mesmo ano, a média municipal dos benefícios por família era de $R \$ 71,61$. Percebe-se, ainda, a baixa escolaridade média da população com mais de 25 anos, em 2000, com a média de apenas 4,04 anos. A disparidade também é considerável, com municípios obtendo uma média inferior a 0,9 anos e um desvio padrão de 1,29 anos.

Tabela 2 - Estatísticas descritivas das variáveis utilizadas

\begin{tabular}{|c|c|c|c|c|c|}
\hline Variável & Observações & Média & $\begin{array}{l}\text { Desvio } \\
\text { padrão }\end{array}$ & $\begin{array}{l}\text { Míni- } \\
\text { mo }\end{array}$ & Máximo \\
\hline Dilma 2010.2 & 5.564 & 0,595 & 0,154 & 0,197 & 0,965 \\
\hline Serra 2010.2 & 5.564 & 0,405 & 0,154 & 0,035 & 0,803 \\
\hline alcanceBF & 5.564 & 0,348 & 0,204 & 0,001 & 0,922 \\
\hline BFpercap & 5.564 & 71,61 & 42.82 & 0,181 & 195,73 \\
\hline crescPIB & 5.560 & 0,4189 & 0,79 & $-0,8936$ & 25,4697 \\
\hline PIBpercap & 5.564 & $10.374,86$ & $11.796,23$ & $1.721,23$ & $288.370,8$ \\
\hline Rdom & 5.564 & 498,87 & 241,01 & 112,2 & $2.043,74$ \\
\hline ExtPob2000 & 5.564 & 20,695 & 17,217 & 0 & 77,22 \\
\hline ExtPob2010 & 5.564 & 11,343 & 11,768 & 0 & 69,670 \\
\hline govPT & 5.564 & 0,158 & 0,365 & 0 & 1 \\
\hline prefPT & 5.564 & 0,101 & 0,301 & 0 & 1 \\
\hline pref*govPT & 5.564 & 0,024 & 0,152 & 0 & 1 \\
\hline Educ & 5.507 & 4,039 & 1,288 & 0,81 & 9,65 \\
\hline Pentecost & 5.473 & 8,26 & 5,56 & 0,05 & 46,10 \\
\hline Nbranco & 5.505 & 46,769 & 25,262 & 0,070 & 98,740 \\
\hline $\operatorname{Idh} 2000$ & 5.507 & 0,699 & 0,083 & 0,467 & 0,919 \\
\hline Gini & 5.507 & 0,561 & 0,059 & 0,360 & 0,820 \\
\hline Lula 2006.2 & 5.564 & 0,619 & 0,170 & 0,149 & 0,972 \\
\hline Alckmin 2006.2 & 5.564 & 0,381 & 0,170 & 0,028 & 0,851 \\
\hline
\end{tabular}

Fonte: Elaboração própria a partir de dados do TSE, do IBGE, do IPEA e da CGU.

A função utilizada, na análise empírica, é a logística. A variável dependente é: Dilma 2010.2, que corresponde à razão entre os votos obtidos por Dilma no segundo turno e o total de votos válidos nas eleições de 2010 no município i. Entre as variáveis explicativas, temos: a) $B F$, que assume, em alguns testes, o alcance 
do PBF (proporção de famílias beneficiadas) e, em outros, o valor destinado a esse programa dividido pela população em 2010; b) crescPIB, que é a taxa de crescimento real do PIB per capita entre 2002 e 2008; c) um vetor de variáveis de cunho socioeconômico (educação, desigualdade, proporção de evangélicos e não brancos, etc.); d) um conjunto de dummies políticas (assumindo 1 se o prefeito do município i é do PT e 0, caso contrário, por exemplo); e e) dummies para cada região geográfica (Sudeste é a categoria de referência).

Em outras especificações, acrescentou-se como variável explicativa a proporção de votos em Lula no segundo turno de 2006, a fim de frisar a semelhança entre o eleitorado petista naquele momento e em 2010, e também de controlar para o chamado efeito Lula sobre a eleição de Dilma, independentemente dos determinantes econômicos e sociais, que também captura parte do incumbent effect, como discutido anteriormente.

Grande parte da literatura que aborda esse tipo de discussão emprega o método de mínimos quadrados ordinários, visto que as variáveis explicativas são provavelmente exógenas em relação à variável explicada, não violando essa premissa de exogeneidade das variáveis explicativas (a proporção de votos válidos obtidos por Dilma não exerce efeito sobre nenhuma das variáveis explicativas).

Entretanto, optou-se pelo uso da regressão beta, que, como apontado por Ferrari e Cribari-Neto (2004 ${ }^{6}$ apud CRIBARI-NETO; ZEILEIS, 2010), é uma metodologia mais adequada à modelagem quando a variável dependente é uma taxa ou proporção. ${ }^{7} \mathrm{O}$ método de regressão beta permite que se acomode a assimetria típica de distribuições de variáveis medidas no intervalo $(0,1),{ }^{8}$ é interpretável em termos da média da variável dependente ${ }^{9} \mathrm{e}$, finalmente, é naturalmente heterocedástico. Esse modelo apresenta a seguinte função densidade (1): ${ }^{10}$

$$
f(y ; \mu, \phi)=\frac{\Gamma(\phi)}{\Gamma(\mu \phi) \Gamma((1-\mu) \phi)} y^{\mu \phi-1}(1-y)^{(1-\mu) \phi-1}, \text { com } 0<\mathrm{y}<1
$$

6 FERRARI, S. L. P.; CRIBARI-NETO, F. Beta regression for modelling rates and proportions. Journal of Applied Statistics, v. 31, n. 7, p. 799-815, 2004.

7 Dessa forma, evita-se uma das ameaças internas ao modelo de regressão, a saber, a especificação errônea da equação de regressão por inadequação da especificação à medida da variável dependente.

8 "The chief motivation for the beta regression model lies in the flexibility delivered by the assumed beta Law. The beta density can assume a number of different shapes depending on the combination of parameter values, including left and right skewed or the flat shape of the uniform density [...]”. (CRIBARI-NETO; ZEILEIS, 2010, p. 2).

9 Geralmente, algumas variáveis são transformadas de forma a se adequarem a esse intervalo (como no caso da transformação logística). No presente caso, contudo, a variável já é limitada ao intervalo $(0,1)$.

10 A explicação da metodologia a seguir segue de perto as referências citadas. 
Para uma variável aleatória e independente $\mathrm{y}_{\mathrm{i}}=\mathrm{y}_{1}, \ldots, \mathrm{y}_{\mathrm{n}}$, a função de densidade tem média $\mu(0<\mu<1)$ e precisão desconhecida $\varphi(\phi>0)^{11} \mathrm{e}$ variância $\operatorname{Var}\left(y_{i}\right)=\frac{\mu_{i}\left(1-\mu_{i}\right)}{1+\phi}$.

Assumindo-se que a média segue uma função g(.) estritamente monotônica e diferenciável até segunda ordem, de forma que $g\left(\mu_{i}\right)=\sum_{i=1}^{k} x_{i} \beta_{i}$, basta escolher a função g(.) para se estimar o modelo. ${ }^{12}$

No presente caso, a função escolhida foi a logística, de forma que $g\left(\mu_{i}\right)=\log \left(\frac{\mu_{i}}{1-\mu_{i}}\right)$. Essa escolha ocorreu por ser a mais utilizada em estudos empíricos que utilizam a metodologia de regressão beta. A equação 2 especifica $g\left(\mu_{i}\right)$ :

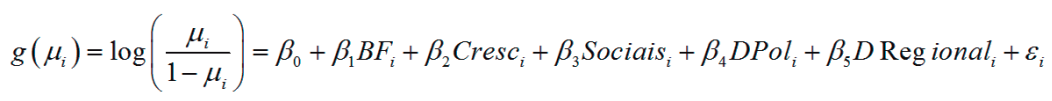

em que $\mathrm{BF}_{i}$ é uma medida do $\mathrm{PBF}$ (alcance do $\mathrm{PBF}$ ou recursos do bolsa família per capita) do município i; Cresc $_{i}$ é o crescimento médio do PIB per capita do município $i$ entre os anos 2002 e 2008; Sociais $_{i}$ são variáveis sociais do município $i$ como proporção de não brancos na população total, nível médio de escolaridade de seus habitantes, proporção de pentecostais, IDH e interação do BF com o Gini; $D P O_{i}$ são variáveis dummies políticas relacionadas ao partido político do município e do

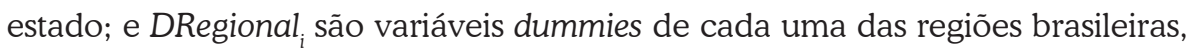
sendo a Sudeste a região de referência. O método de estimação é o de máxima verossimilhança. Para o cálculo dos efeitos marginais foi utilizada a seguinte equação:

$$
\frac{\partial \mu_{i}}{\partial x_{i}}=\beta_{i} \frac{e^{g\left(\mu_{i}\right)}}{\left(1+e^{g\left(\mu_{i}\right)}\right)^{2}}
$$

Os efeitos marginais calculados estão no Apêndice A deste artigo (ver Tabelas 8 a 12). Referências a eles serão realizadas na exposição dos resultados na próxima seção. ${ }^{13}$

11 Quanto maior o valor de $\varphi$, maior a precisão do modelo obtido em relação à função g(.) adotada.

12 Dentre as diversas funções que podem ser usadas nesse modelo estão a logit, a probit, a log-log, a log-log complementar e a Cauchy.

13 Os parâmetros de precisão são reportados, mas como não se comparam diferentes funções g(.) neste trabalho, não serão comentados. 


\section{Resultados}

\subsection{Discussão lnicial ${ }^{14}$}

Nota-se, na parte superior da Figura 1, uma elevada correlação entre a proporção de votos obtidos por Lula, no segundo turno de 2006, e por Dilma no primeiro (superior esquerdo) e no segundo (superior direito) turno de 2010, nos municípios brasileiros. Os coeficientes de correlação são 0,81 e 0,88, respectivamente. A proporção para Lula está no eixo vertical e, para Dilma, no eixo horizontal.

Figura 1 - Persistência dos votos do PT e do PSDB
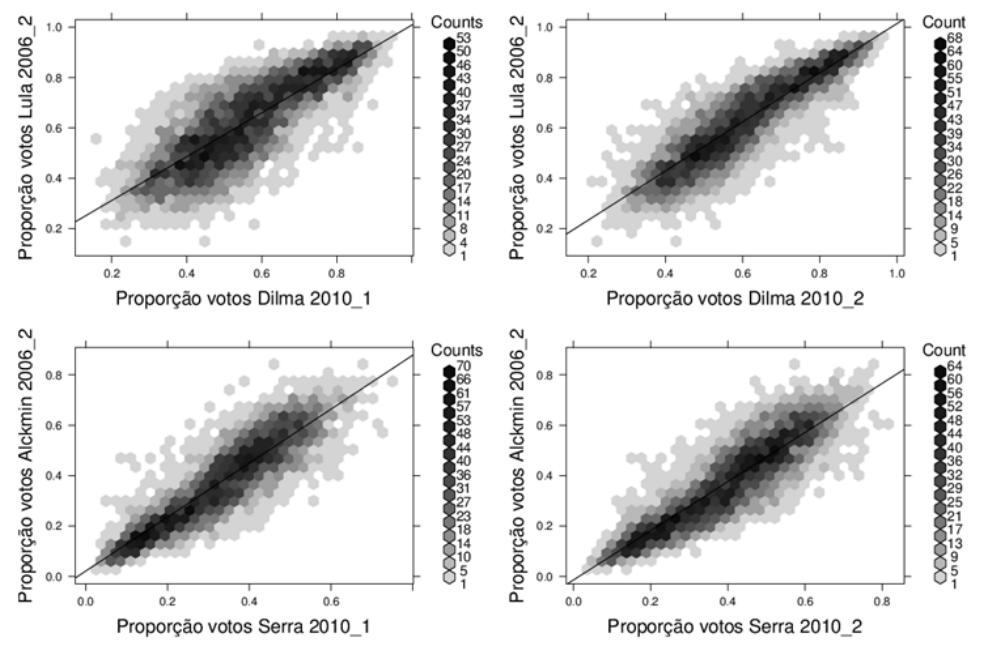

Fonte: Elaboração própria a partir de dados do Tribunal Superior Eleitoral (2010).

Há duas possibilidades (não mutuamente exclusivas, com provável elevada correlação entre elas) para essa semelhança no padrão de votação: os mesmos fatores sociais e econômicos que levaram as regiões menos desenvolvidas a eleger Lula foram importantes na eleição de Dilma (nomeadamente, o crescimento da economia e a grande expansão dos programas de transferência de renda); e/ou o eleitorado de Lula se manteve fiel, e o apoio incondicional do então presidente à candidata do PT favoreceu, por si só, a votação em Dilma, independentemente das condições econômicas e da obtenção de benefícios. Neste caso, o eleitorado interpretou que, apesar da troca de presidente, o governo Dilma seria de continuidade em relação ao seu antecessor. Ferreira, Sakurai e Oliveira (2011) sugerem que uma associação desses dois efeitos foi relevante para o sucesso de Dilma nas eleições.

14 Esta subseção se baseia em Pereira, Nakabashi e Shikida (2011). 
Na parte inferior da Figura 1 estão apresentadas as relações entre a proporção de votos para Alckmin no segundo turno, em 2006, e para Serra no primeiro (inferior esquerdo) e no segundo (inferior direito) turnos para os municípios brasileiros. A proporção para Alckmin está no eixo vertical, enquanto que para Serra está no eixo horizontal. A associação linear entre as duas variáveis também é forte e reflete a inércia existente no eleitorado do PSDB. Os coeficientes de correlação são 0,89 e 0,88 , respectivamente. Isso ocorreu pela própria correlação elevada existente no PT, que indica que nos municípios onde a proporção de votos em Lula foi elevada (e, portanto, baixa para Alckmin), em 2006, a tendência foi a mesma para Dilma, em 2010 (sendo baixa para Serra), e vice-versa. Em outras palavras, é provável que os fatores que levaram os eleitores de um determinado município a escolherem Alckmin, em sua maioria, em 2006, também foram importantes na escolha por Serra, em 2010.

Observa-se, na parte superior da Figura 2 (proporção de votos em Dilma no eixo horizontal nos quatro diagramas de dispersão), grande correlação negativa entre a proporção de votos na candidata do PT e o nível de desenvolvimento dos municípios (escolaridade média e IDH). A correlação entre anos de escolaridade (diagrama superior direito) e a proporção dos votos em Dilma é de -0,60, enquanto que entre a última e o IDH (diagrama superior esquerdo) é de -0,67.

Figura 2 - Proporção de votos em Dilma e fatores econômicos e sociais
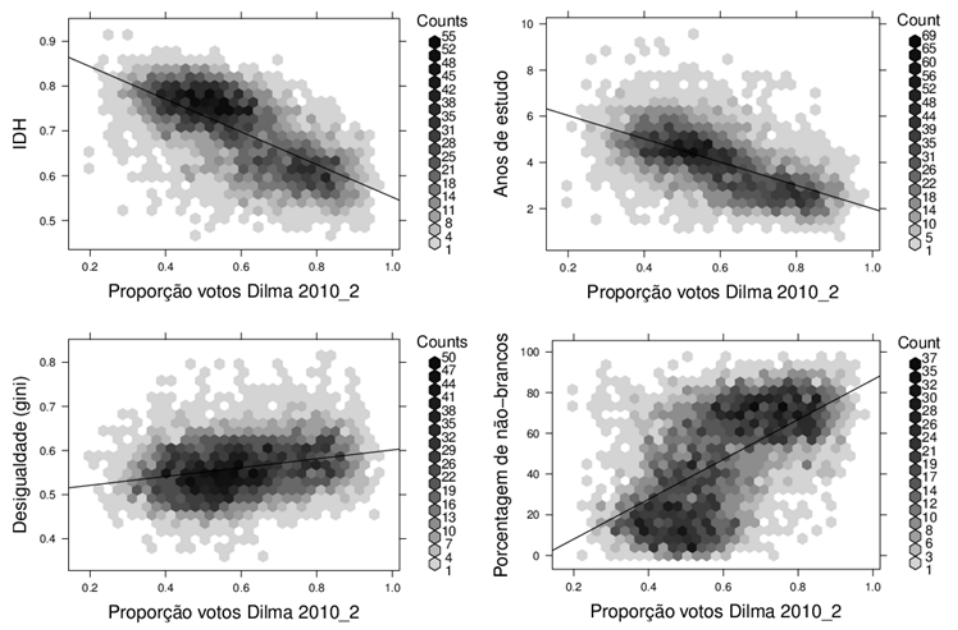

Fonte: Elaboração própria a partir de dados do Tribunal Superior Eleitoral (2010) e IBGE.

A proporção de não brancos está associada positivamente à proporção de votos em Dilma (coeficiente de correlação de 0,60 ), como pode ser visto no quadrante inferior direito da Figura 2 (proporção de não brancos está no eixo verti- 
cal). Essa relação pode ser resultado das políticas de promoção da igualdade racial desenvolvidas durante a última gestão do PT, ou apenas uma consequência da correlação existente entre raça e variáveis socioeconômicas. É interessante notar a polarização existente, em que os municípios que apresentam proporção mais elevada de não brancos foram os mesmos com mais votos em Dilma, enquanto que o outro grupo de municípios, aqueles com menor proporção de não brancos, apresentaram menor votação na candidata do PT. No entanto, considerando cada grupo separadamente, o diagrama de dispersão do lado inferior direito da Figura 2 não apresenta uma tendência clara. Por fim, a associação entre o índice de Gini e a proporção de votos em Dilma no segundo turno é positiva, mas fraca (diagrama inferior esquerdo).

Os diagramas de dispersão apresentados na Figura 2 levam a crer que o cenário eleitoral de 2010 se assemelha fortemente ao de 2006: municípios menos desenvolvidos (com menor IDH em 2000) e com menor escolaridade média da população acima de 25 anos renderam maior proporção de votos à candidata da situação. Naqueles municípios com maiores níveis de escolaridade e desenvolvimento aparentemente prevaleceu o desejo de alternância de poder, refletido na maior proporção de votos em José Serra.

Conforme sinalizam os diagramas de dispersão apresentados na Figura 3 (proporção de votos em Dilma no eixo horizontal, nos quatro diagramas de dispersão), pode-se observar uma correlação alta e positiva entre a proporção de famílias beneficiadas pelo PBF e a votação em Dilma, tanto pela variável que mede o alcance do programa (coeficiente de correlação de 0,72 ), quanto pela que mensura o benefício per capita (coeficiente de correlação de 0,71) por município, com ambas expressas no eixo vertical (diagramas superiores). Cabe ressaltar a existência de polarização em dois grupos semelhante ao apresentado anteriormente, no caso da proporção de não brancos, indicando que comunidades onde existe maior proporção de não brancos são as mesmas que experimentaram o benefício de forma mais acentuada, seja em valor per capita, seja na extensão do programa. 
Figura 3 - Proporção de votos em Dilma, bolsa família e PIB per capita
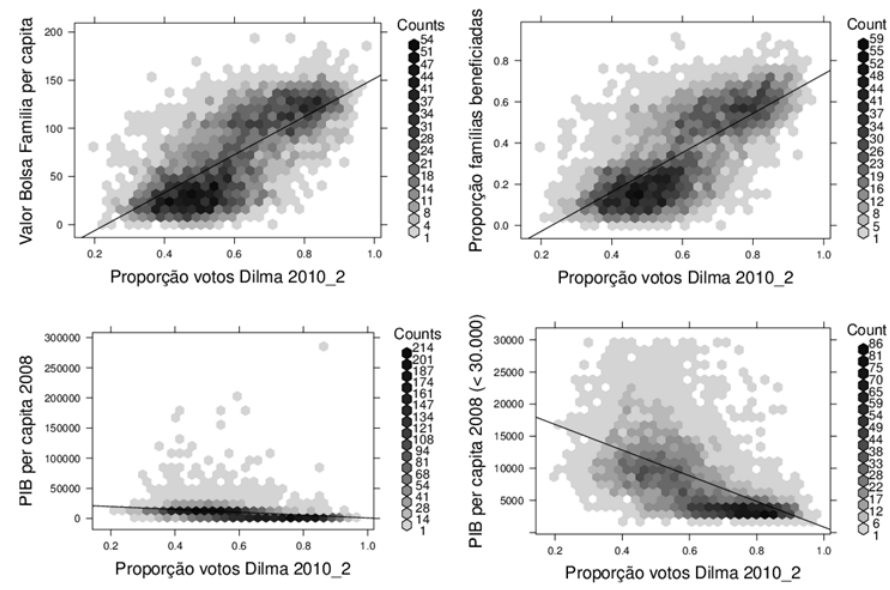

Fonte: Elaboração própria a partir de dados do Tribunal Superior Eleitoral (2010) e IBGE.

Já a possível relação entre os votos no PT e o nível de renda dos municípios não é tão evidente (ver parte inferior da Figura 3). A diferença dos dois diagramas é que o inferior esquerdo apresenta os municípios com PIB per capita de até $R \$ 200.000,00$ em 2008, enquanto que o inferior direito restringe graficamente aqueles com PIB per capita até $\mathrm{R} \$ 30.000,00$, no mesmo ano, para facilitar a visualização da relação entre as duas variáveis. De qualquer forma, percebe-se que os municípios com menores níveis de renda per capita foram aqueles que apresentaram maior proporção de votos na candidata do PT.

Vale destacar que as correlações anteriormente indicadas podem ser decorrentes de viés introduzido por variáveis omitidas que são relevantes para explicar a proporção de votos em cada um dos candidatos e correlacionadas com uma ou mais das variáveis explicativas. Para contornar esse problema, na sequência do trabalho são realizadas estimações acerca da influência das variáveis selecionadas sobre a proporção de votos por meio das regressões beta, o que é essencial ao permitir mensurar o efeito isolado de cada variável sobre a proporção de votos em Dilma, além da utilização de uma série de variáveis de controle socioeconômicas.

\subsection{Resultados Econométricos}

Nas regressões 1 e 2 da Tabela 3, a mensuração da magnitude do PBF é dada pela variável de alcance, enquanto nas equações 3, 4 e 5 é empregado o valor transferido às famílias dividido pela população do município em 2010. Na equação 6, as duas medidas são utilizadas. Em todas as especificações, os coeficientes 
de ambas as variáveis de mensuração da extensão do PBF, alcanceBF e BFpercap, foram positivos e altamente significativos (exceto para BFpercap na equação 6).

Tabela 3 - Resultados das regressões beta

\begin{tabular}{|c|c|c|c|c|c|c|}
\hline \multicolumn{7}{|c|}{ Variável dependente: proporção de votos em Dilma no segundo turno de 2010 (Dilma 2010.2) } \\
\hline & $(1)$ & $(2)$ & (3) & (4) & $(5)$ & $(6)$ \\
\hline \multirow[t]{2}{*}{ alcance_BF } & 2.39 & 2.34 & & & & 1.56 \\
\hline & $3.52 \mathrm{E}-02 * * *$ & $0.0589 * * *$ & & & & $0.1564041^{* * *}$ \\
\hline \multirow[t]{2}{*}{ BFpercap } & & & $9.79 \mathrm{E}-03$ & $8.70 \mathrm{E}-03$ & 6.09E-03 & $5.90 \mathrm{E}-04$ \\
\hline & & & $2.69 \mathrm{E}-04^{* * *}$ & $3.42 \mathrm{E}-04^{* * *}$ & $0.0003584^{* * *}$ & $6.60 \mathrm{E}-04$ \\
\hline \multirow[t]{2}{*}{ crescpibpc2006 } & $-1.53 \mathrm{E}-11$ & $-1.33 \mathrm{E}-11$ & $1.36 \mathrm{E}-12$ & & & \\
\hline & $3.71 \mathrm{E}-11$ & $3.59 \mathrm{E}-11$ & $3.67 \mathrm{E}-11$ & & & \\
\hline \multirow[t]{2}{*}{ pibpercap 2008} & $8.34 \mathrm{E}-07$ & $1.11 \mathrm{E}-06$ & 7.84E-07 & & & \\
\hline & $5.87 \mathrm{E}-07$ & $5.69 \mathrm{E}-07$ & $5.76 \mathrm{E}-07$ & & & \\
\hline \multirow[t]{2}{*}{ govpt2006 } & & $-1.72 \mathrm{E}-01$ & $-1.83 \mathrm{E}-01$ & $-1.89 \mathrm{E}-01$ & $-2.58 \mathrm{E}-01$ & $-2.21 \mathrm{E}-01$ \\
\hline & & $2.06 \mathrm{E}-02 * * *$ & $2.20 \mathrm{E}-02 * * *$ & $2.21 \mathrm{E}-02 * * *$ & $2.16 \mathrm{E}-02 * * *$ & $2.17 \mathrm{E}-02 * * *$ \\
\hline \multirow[t]{2}{*}{ pref_PT } & & $-4.01 \mathrm{E}-02$ & $7.70 \mathrm{E}-03$ & $1.01 \mathrm{E}-02$ & $-1.96 \mathrm{E}-02$ & $-2.05 \mathrm{E}-02$ \\
\hline & & $2.00 \mathrm{E}-02^{*}$ & $2.29 \mathrm{E}-02$ & $2.31 \mathrm{E}-02$ & $2.25 \mathrm{E}-02$ & $2.23 \mathrm{E}-02$ \\
\hline \multirow[t]{2}{*}{ Prefgovpt } & & & $-2.36 \mathrm{E}-01$ & $-2.36 \mathrm{E}-01$ & $-2.22 \mathrm{E}-01$ & $-2.10 \mathrm{E}-01$ \\
\hline & & & $4.93 \mathrm{E}-02 * * *$ & $4.93 \mathrm{E}-02 * * *$ & $4.77 \mathrm{E}-02 * * *$ & $4.73 \mathrm{E}-02 * * *$ \\
\hline \multirow[t]{2}{*}{ Norte } & & $-2.66 \mathrm{E}-01$ & $-9.14 \mathrm{E}-02$ & $-9.04 \mathrm{E}-02$ & $-2.42 \mathrm{E}-01$ & $-3.31 \mathrm{E}-01$ \\
\hline & & $2.85 \mathrm{E}-02 * * *$ & $2.75 \mathrm{E}-02 * * *$ & $2.75 \mathrm{E}-02 * *$ & $2.88 \mathrm{E}-02 * * *$ & $2.98 \mathrm{E}-02 * * *$ \\
\hline \multirow[t]{2}{*}{ Nordeste } & & $1.28 \mathrm{E}-01$ & $2.41 \mathrm{E}-01$ & $2.50 \mathrm{E}-01$ & $1.70 \mathrm{E}-01$ & $9.33 \mathrm{E}-02$ \\
\hline & & $2.65 \mathrm{E}-02 * * *$ & $2.59 \mathrm{E}-02 * * *$ & $2.60 \mathrm{E}-$ & $2.59 \mathrm{E}-02 * * *$ & $2.68 \mathrm{E}-02 * * *$ \\
\hline \multirow[t]{2}{*}{ Sul } & & $-5.00 \mathrm{E}-03$ & $-3.91 \mathrm{E}-02$ & $-4.29 \mathrm{E}-02$ & $1.11 \mathrm{E}-01$ & $1.14 \mathrm{E}-01$ \\
\hline & & $1.68 \mathrm{E}-02$ & $1.70 \mathrm{E}-02 *$ & $1.71 \mathrm{E}-02 *$ & $1.88 \mathrm{E}-02 * * *$ & $1.86 \mathrm{E}-02^{* * *}$ \\
\hline \multirow[t]{2}{*}{ Centro-oeste } & & $-2.39 \mathrm{E}-01$ & $-2.48 \mathrm{E}-01$ & $-2.39 \mathrm{E}-01$ & $-3.18 \mathrm{E}-01$ & $-2.95 \mathrm{E}-01$ \\
\hline & & $2.29 \mathrm{E}-02 * * *$ & $2.34 \mathrm{E}-02 * * *$ & $2.37 \mathrm{E}-02 * * *$ & $2.39 \mathrm{E}-02 * * *$ & $2.38 \mathrm{E}-02 * * *$ \\
\hline \multirow[t]{2}{*}{ educ_2000 } & & & & $-3.80 \mathrm{E}-02$ & $-3.45 \mathrm{E}-02$ & $-9.49 \mathrm{E}-03$ \\
\hline & & & & $8.46 \mathrm{E}-04^{* * *}$ & $8.26 \mathrm{E}-04^{* * *}$ & $8.54 \mathrm{E}-03$ \\
\hline \multirow[t]{2}{*}{ Pent } & & & & & $-7.29 \mathrm{E}-03$ & $-7.57 \mathrm{E}-03$ \\
\hline & & & & & $1.25 \mathrm{E}-03^{* * *}$ & $1.24 \mathrm{E}-03^{* * *}$ \\
\hline \multirow[t]{2}{*}{ Nonwhite } & & & & & $9.29 \mathrm{E}-03$ & $8.16 \mathrm{E}-03$ \\
\hline & & & & & $4.62 \mathrm{E}-04^{* * *}$ & $4.71 \mathrm{E}-04^{* * *}$ \\
\hline \multirow[t]{2}{*}{ Constant } & $-4.29 \mathrm{E}-01$ & $-3.78 \mathrm{E}-01$ & $-3.00 \mathrm{E}-01$ & $-6.25 E-02$ & $-2.36 \mathrm{E}-01$ & $-4.07 \mathrm{E}-01$ \\
\hline & $1.65 \mathrm{E}-02 * * *$ & $1.99 \mathrm{E}-02 * * *$ & $1.94 \mathrm{E}-02 * * *$ & $5.25 \mathrm{E}-02$ & $5.26 \mathrm{E}-02 * * *$ & $5.47 \mathrm{E}-02 * * *$ \\
\hline Obs & 5564 & 5564 & 5564 & 5507 & 5471 & 5471 \\
\hline \multirow{3}{*}{$\begin{array}{l}\text { Pseudo-R }{ }^{2} \\
\text { (phi) }\end{array}$} & 0.5127 & 0.5484 & 0.5315 & 0.5328 & 0.5632 & 0.5724 \\
\hline & 18.7793 & 20.292 & 19.5895 & 19.6132 & 21.1366 & 21.5361 \\
\hline & $0.3478^{* * *}$ & $0.3765^{* * *}$ & $0.3632 * * *$ & $0.3655^{* * *}$ & $0.3958 * * *$ & $0.4035^{* * *}$ \\
\hline
\end{tabular}

Nota: A notação para a significância estatística em todas as tabelas é: *** significativo ao nível 0,1\%; ** significativo ao nível de $1 \%$; * significativo ao nível de $5 \% .{ }^{15}$

Nas duas primeiras colunas, os resultados indicam que quanto maior a proporção de famílias beneficiadas pelo programa em determinado município, maior a proporção de votos direcionados a então candidata Dilma. Já o crescimento do PIB municipal no período que antecedeu as eleições e o nível do PIB per capita não foram significativos na determinação da proporção de votos destinados à candidata do PT.

15 Utilizamos o $R$ para as estimações das regressões beta e para o cálculo dos efeitos marginais. Ver Cribari-Neto e Zeileis (2010) e Gruen, Kosmidis e Zeileis (2012). 
Um resultado curioso é o sinal das dummies políticas: de acordo com a segunda especificação, a presença do PT nos governos do município e do estado tem efeitos negativos sobre a probabilidade de eleição de Dilma. Esse mesmo resultado é encontrado por Canêdo-Pinheiro (2009) ao empregar dados da reeleição de Lula em 2006. Esses resultados podem refletir maior insatisfação com o partido por parte da população que tem maior proximidade com ele.

Nas duas primeiras estimações, os efeitos marginais calculados (ver Apêndice A) indicam que uma elevação de 1 ponto percentual (p.p.) no alcance do PBF tem um efeito positivo na proporção de votos da candidata Dilma, de 0,57 p.p. e 0,56 p.p., respectivamente. ${ }^{16}$

Nas colunas 3, 4 e 5, o PBF - agora medido pelo valor destinado às transferências do programa sobre o número de habitantes do município - apresentou um impacto positivo e estatisticamente significativo sobre a variável explicada. Nessas três regressões, os gastos com o PBF per capita apresentam coeficientes positivos e significativos, indicando que, quanto maior o volume de transferências realizadas (em termos per capita) no município, maior a parcela de votos em Dilma, mesmo levando em conta o PIB per capita e seu crescimento, o cenário político municipal e estadual, a escolaridade média da população, a proporção de negros e de pentecostais, bem como outras especificidades regionais.

No entanto, o efeito da variável BFpercap é bem menor em relação ao seu alcance: uma elevação de 100 reais na média dos valores desses benefícios, o que representa um aumento de $140 \%$, pois, em 2010, o valor médio da bolsa família era de $R \$ 71,63$, tem um efeito positivo na proporção de votos de 0,23 p.p., 0,21 p.p., e 0,15 p.p. nas equações 3, 4 e 5, respectivamente. Nos resultados apresentados na coluna 6, nota-se que, quando as duas variáveis utilizadas para mensurar o impacto do PBF são empregadas na mesma especificação, ocorre uma redução na magnitude do efeito de ambas, mas principalmente da variável BFpercap.

Na última especificação, uma elevação de 1 p.p. no seu alcance tem um efeito sobre a proporção de votos em Dilma em 0,37 p.p., enquanto que um aumento médio de $\mathrm{R} \$ 100,00$ no valor desse benefício, controlando para o número de famílias que o recebem, traz um efeito positivo no regressando de apenas 0,0014 p.p. Esse resultado é um forte indicador de que elevações no valor per capita do bolsa família sem alterações no número de famílias que o recebem têm um efeito próximo de zero sobre a proporção de votos de Dilma, pois quem recebe já teria uma propensão a votar no governo de situação para minimizar a probabilidade de

16 Os resultados dos efeitos marginais estão apresentados nas Tabelas 9 a 12, no Apêndice A. Os efeitos marginais foram calculados com base na equação 3 e de acordo com a média das variáveis de todos os municípios. Os efeitos marginais das regressões beta dependem dos valores de todos os regressores e, desse modo, o efeito é diferente para cada município e especificação. Como são muitos municípios, optou-se por calcular apenas os efeitos marginais de acordo com a média dos regressores. 
perda do benefício, independentemente do valor. Por se tratar de uma população de renda baixa, pequenos benefícios monetários seriam suficientes para influenciar na escolha do candidato. Por outro lado, nossos resultados sugerem que uma elevação do alcance, mesmo mantendo o montante do benefício per capita constante, teria um efeito considerável.

Os resultados da regressão 4 fornecem indícios de que a maior escolaridade reduz a probabilidade de eleição de Dilma. O efeito marginal de educ é de -0,0091, ou seja, cada ano de estudo a mais na escolaridade média da população municipal reduz, em média, a proporção de votos em Dilma em 0,009 p.p., sendo esse efeito bem reduzido, ainda mais quando se considera a baixa escolaridade média municipal no Brasil. Adicionalmente, na coluna 6, a variável educ perde significância.

Nas duas últimas regressões da Tabela 3, são acrescentadas como variáveis de controle a proporção de evangélicos de origem pentecostal e a proporção de não brancos na população dos municípios. Ambos os coeficientes são estatisticamente significativos e apresentam os mesmos sinais encontrados pela literatura que investiga os determinantes da reeleição de Lula em 2006. Enquanto a proporção de não brancos na população tem impacto positivo sobre a proporção municipal de votos em Dilma, a proporção de evangélicos tem efeito negativo. Aparentemente, o desempenho eleitoral de Dilma foi relativamente melhor nos municípios com maior participação de negros, pardos e índios na população, provavelmente em decorrência das ações implementadas durante a era Lula voltadas à questão da desigualdade racial. Outra possibilidade é a correlação negativa da proporção de não brancos com nível de escolaridade e outras variáveis socioeconômicas, como ressaltado anteriormente.

Nas regressões 2 a 6, os coeficientes das dummies para municípios pertencentes às regiões Norte, Centro-Oeste e Sul foram negativos (com exceção do Sul na coluna 2, que se mostrou não significativo), e os coeficientes da dummy para municípios do Nordeste foram positivos e significativos em todas as especificações. Desse modo, há indícios de que, mesmo controlando para o alcance do PBF, para o nível de produto per capita e seu crescimento, e para a presença de governantes do PT, os municípios do Nordeste têm uma propensão maior a votar em Dilma em relação ao Sudeste, enquanto municípios das demais regiões apresentam, em média, o comportamento oposto. Considerando que Dilma não obteve uma vantagem considerável na média dos municípios da região sudeste, esses resultados também reforçam a ideia discutida pelos partidos em períodos eleitorais da importância da região nordeste na determinação do resultado eleitoral.

A Tabela 4 inclui como variável explicativa, a exemplo da literatura, a fração de votos obtida pelo candidato do PT na eleição imediatamente anterior. ${ }^{17}$ Dessa

17 Todos os autores mencionados da literatura nacional incluem o percentual de votos recebidos por Lula em 2002 na análise dos determinantes da reeleição de Lula em 2006. 
forma, pode-se investigar em que medida a divisão dos votos entre PT e PSDB, no final de 2006, influenciou a votação de Dilma (uma espécie de efeito inercial político que também captura parte do incumbent effect). Os resultados sugerem que há uma considerável semelhança entre o padrão eleitoral das últimas duas eleições: mesmo incluindo a escolaridade, o PBF e outras variáveis de controle, o efeito Lula prevalece. Porém, o coeficiente da variável Lula 2006.2 pode captar o efeito de outras variáveis de difícil mensuração, que foram determinantes para a reeleição de Lula e também o foram para a eleição de Dilma, além do efeito ressaltado por Zucco (2008) de que a população de renda mais baixa tende a votar no candidato de situação.

Tabela 4 - Resultados das regressões Beta com efeito Lula

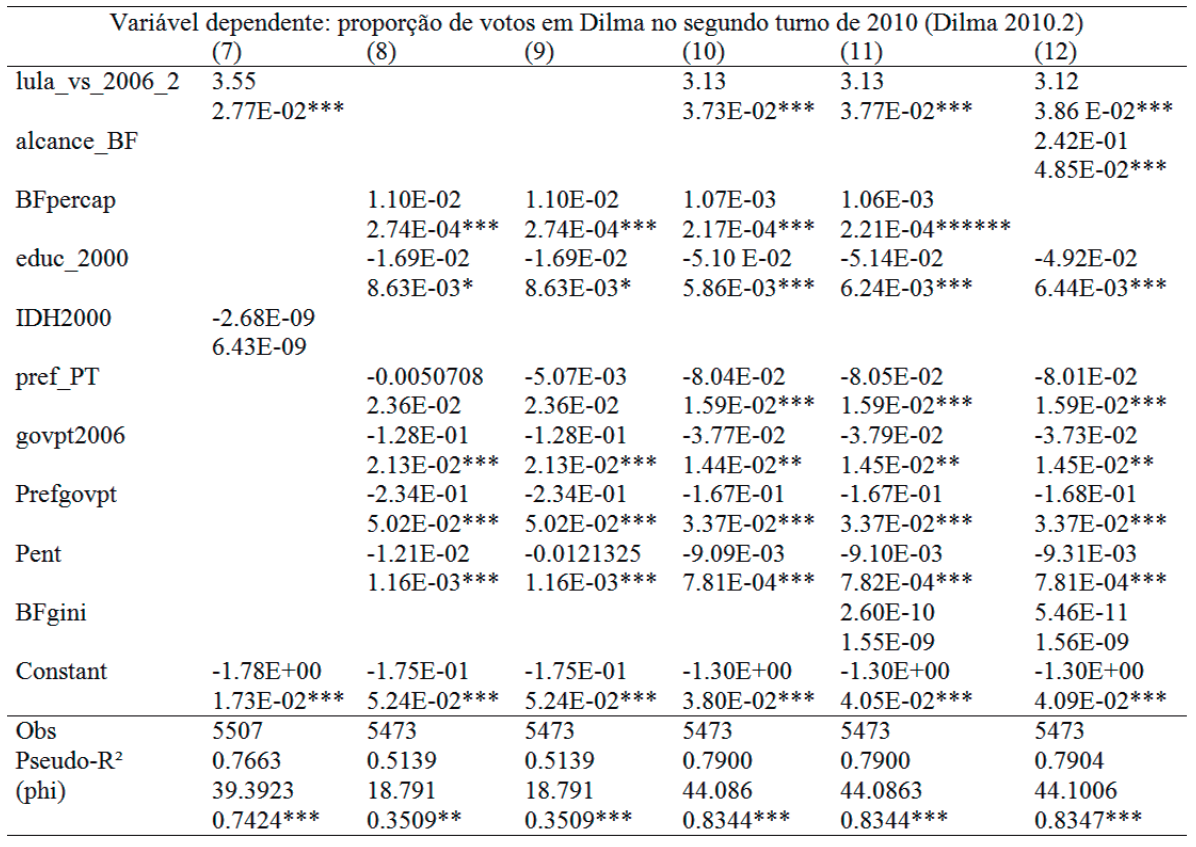

Nota: A notação para a significância estatística em todas as tabelas é: *** significativo ao nível de $0,1 \% ;{ }^{* *}$ significativo ao nível de $1 \% ;{ }^{*}$ significativo ao nível de $5 \%$.

A inclusão da proporção de votos de Lula, em 2006, melhora o ajuste das regressões (pseudo- $\mathrm{R}^{2}$ ao redor de 0,80). Nas especificações 7, 10, 11 e 12 da Tabela 4, os coeficientes de Lula 2006.2 indicam que a proporção de votos em Dilma em 2010 foi maior nos municípios em que houve uma votação expressiva em Lula no segundo turno das eleições presidenciais de 2006. O coeficiente da variável Lula 2006.2 permanece praticamente inalterado nas diferentes especificações, indicando a robustez dos resultados. Na coluna 7, o coeficiente da variável Lula2006.2 
apresenta o sinal esperado e o efeito marginal indica que uma elevação de 1 p.p. nos votos em Lula, em 2006, leva a um aumento na proporção de votos em Dilma, em 2010, de 0,74 p.p.

Nas três últimas especificações, verifica-se que a disseminação do PBF é relevante na determinação da probabilidade de eleição de Dilma, mesmo controlando para o efeito Lula e demais variáveis. Os coeficientes de BFpercap nas colunas 10 e 11 permanecem positivos e significativos, embora o impacto dessa variável se mostre inferior ao estimado nas regressões sem o efeito Lula (colunas 8 e 9). $\mathrm{Na}$ última coluna, pode-se constatar que o alcance do PBF também continua positivo e significativo, mas com considerável redução em sua magnitude. Controlando para o efeito Lula e considerando os efeitos marginais apresentados na Tabela 10 do Apêndice A, uma elevação em 1 p.p. no alcance do programa leva a uma elevação média da proporção de votos em Dilma de 0,56 p.p., ou seja, continua a ser um efeito importante.

Quanto às regressões 8 e 9, os resultados são similares àqueles obtidos na Tabela 3: o programa de transferência tem impacto positivo sobre a proporção municipal de votos na candidata da situação. ${ }^{18} \mathrm{O}$ coeficiente da variável de controle pentecost manteve seu sinal negativo e magnitude muito semelhante. Inclui-se, ainda, nas regressões, com os resultados apresentados nas colunas 11 e 12, a variável de interação entre a cobertura do PBF e o índice de Gini municipal ( $B F^{*}$ gini) com o objetivo de mensurar se o impacto do bolsa família seria mais expressivo nos municípios que possuem maior desigualdade de renda. No entanto, os coeficientes não são estatisticamente diferentes de zero.

Nos resultados da Tabela 4, as três dummies políticas apontam para um impacto negativo da presença do PT nos governos estaduais e nas prefeituras sobre a probabilidade de eleição da candidata petista, e esse efeito é ainda maior quando ambas as esferas estão sob a gestão do partido (pref"gouPT tem coeficiente negativo e significativo). Ou seja, esses municípios - com prefeitura e governo geridos pelo PT na ocasião da eleição - tiveram, em média, uma menor proporção de votos em Dilma no segundo turno das eleições de 2010, ceteris paribus. Como destacado anteriormente, a presença mais próxima do eleitor ao partido pode gerar maior nível de rejeição deste, explicando, pelo menos em parte, esses resultados.

O coeficiente negativo e significativo de educ nas colunas 8 a 12 evidencia, mais uma vez, que a maior escolaridade da população reduz a probabilidade de eleição da sucessora de Lula nos municípios. Esse resultado corrobora a hipótese de Zucco (2008) de que populações menos educadas tendem a ser mais depen-

18 Os efeitos marginais para BFpercap nessas duas especificações indicam que o aumento de $\mathrm{R} \$$ 100,00 nessa variável gera um aumento na proporção de votos da candidata Dilma em 0,26 p.p e 0,24 p.p, respectivamente. Dessa forma, apesar de positivo e significativo, o efeito do valor per capita é reduzido. 
dentes do Estado e, portanto, o desempenho eleitoral é relativamente mais favorável ao candidato da situação nos municípios com menor escolaridade.

\section{Checagem de Robustez}

Os resultados presentes nas Tabelas 3 e 4 podem conter estimativas enviesadas dos efeitos do PBF sobre os votos recebidos por Dilma em decorrência de variáveis omitidas que estejam correlacionadas com as variáveis que capturam o efeito do programa de transferência de renda e que sejam importantes na determinação da proporção de votos em cada candidato como, por exemplo, a prevalência e a incidência de pobreza nos municípios do país. A prevalência e a incidência pobreza estão correlacionadas tanto com a abrangência do PBF nos munícipios, quanto com a proporção de votos recebida por cada candidato. A primeira correlação emerge da natureza do programa, enquanto a segunda pode ser atribuída, por exemplo, ao histórico do PT de defesa e de desenvolvimento de políticas sociais pró-pobres e pelo fato da população de renda baixa preferir votar no candidato da situação, como sugerido pelos resultados encontrado por Zucco (2008).

Considerando a possibilidade anteriormente apontada, os coeficientes estimados e apresentados na seção anterior podem conter não apenas informações do efeito bolsa família sobre os votos em Dilma, mas também informações do efeito das preferências políticas das pessoas residentes em municípios mais pobres do país, uma vez que as estimações realizadas não apresentam controles para a incidência e prevalência de pobreza.

Para contornar essa situação, foram introduzidos variáveis de controle que capturam a prevalência e incidência da pobreza nos municípios brasileiros. As variáveis utilizadas com esse objetivo foram os percentuais de pessoas extremamente pobres em 2000 e em 2010. A variável de 2000 foi empregada para controlar o histórico de pobreza dos municípios brasileiros, enquanto a porcentagem de 2010 foi utilizada para capturar a prevalência da pobreza na ocasião da eleição.

Além disso, as estimativas foram realizadas sem as variáveis de crescimento do PIB e do PIB per capita. No último caso, realizou-se a substituição pela variável renda domiciliar per capita em 2010, com o objetivo secundário de verificar se as estimativas obtidas anteriormente são imunes ao fato do PIB per capita conter a "renda líquida envidada ao exterior". Principalmente no caso de municípios menores, a sua validade como variável proxy para renda local pode ser questionável, já que boa parte dela poderia ser remetida ao exterior.

Os resultados com esses controles adicionais estão nas Tabelas de 5 a $7 .{ }^{19} \mathrm{~A}$ primeira apresenta as estimativas com os controles de prevalência e incidência de

19 As Tabelas de 10 a 12 apresentam os efeitos marginais das estimações da checagem de robustez. 
pobreza, sem as variáveis de PIB e renda domiciliar. Já a Tabela 6 apresenta as estimativas incluindo a renda domiciliar per capita. A Tabela 7 traz as estimativas de equações com a presença da variável que captura o efeito Lula e com os controles para pobreza.

Tabela 5 - Resultados das regressões beta com controles para pobreza extrema em 2000 e 2010

\begin{tabular}{|c|c|c|c|c|c|c|}
\hline \multicolumn{7}{|c|}{ Variável dependente: proporção de votos em Dilma no segundo turno de 2010 (Dilma 2010.2) } \\
\hline & $(1)$ & (2) & (3) & (4) & (5) & (6) \\
\hline \multirow[t]{2}{*}{ alcance_BF } & 2.18 & 2.24 & & & & 1.40 \\
\hline & $4.99 \mathrm{E}-02 * * *$ & $6.11 \mathrm{E}-02 * * *$ & & & & $1.59 \mathrm{E}-01 * * *$ \\
\hline \multirow[t]{2}{*}{ BFpercap } & & & $9.27 \mathrm{E}-03$ & 8.37E-03 & $5.93 \mathrm{E}-03$ & $1.01 \mathrm{E}-03$ \\
\hline & & & $2.72 \mathrm{E}-05^{* * *}$ & $3.42 \mathrm{E}-04^{* * * *}$ & $3.58 \mathrm{E}-04^{* * *}$ & $6.66 \mathrm{E}-04$ \\
\hline \multirow[t]{2}{*}{ crescpibpc2006_ } & $-1.56 \mathrm{E}-11$ & $-1.56 \mathrm{E}-11$ & $-4.19 \mathrm{E}-12$ & & & \\
\hline & $3.70 \mathrm{E}-11$ & $3.58 \mathrm{E}-11$ & $3.64 \mathrm{E}-11$ & & & \\
\hline \multirow[t]{2}{*}{ pibpercap 2008} & $6.49 \mathrm{E}-07$ & $1.02 \mathrm{E}-06$ & $7.62 \mathrm{E}-07$ & & & \\
\hline & $5.85 \mathrm{E}-07$ & $5.67 \mathrm{E}-07$ & $5.72 \mathrm{E}-07$ & & & \\
\hline \multirow[t]{2}{*}{ govpt2006 } & & $-1.70 \mathrm{E}-01$ & $-1.76 \mathrm{E}-01$ & $-1.81 \mathrm{E}-01$ & $-2.50 \mathrm{E}-01$ & $-2.20 \mathrm{E}-01$ \\
\hline & & $2.06 \mathrm{E}-02 * * *$ & $2.21 \mathrm{E}-02 * * *$ & $2.20 \mathrm{E}-02 * * *$ & $2.16 \mathrm{E}-02 * * *$ & $2.17 \mathrm{E}-02^{* * * *}$ \\
\hline \multirow[t]{2}{*}{ pref_PT } & & $-4.21 \mathrm{E}-02$ & $5.11 \mathrm{E}-03$ & $6.54 \mathrm{E}-03$ & $-2.09 \mathrm{E}-02$ & $-2.13 \mathrm{E}-02$ \\
\hline & & $2.00 \mathrm{E}-02 *$ & $2.28 \mathrm{E}-02$ & $2.29 \mathrm{E}-02$ & $2.24 \mathrm{E}-02$ & $2.22 \mathrm{E}-02$ \\
\hline \multirow[t]{2}{*}{ Prefgovpt } & & & $-2.39 \mathrm{E}-01$ & $-2.37 \mathrm{E}-01$ & $-2.24 \mathrm{E}-01$ & $-2.12 \mathrm{E}-01$ \\
\hline & & & 4.89E-02*** & $4.90 \mathrm{E}-02 * * *$ & $4.75 \mathrm{E}-02^{* * *}$ & $4.72 \mathrm{E}-02 * * *$ \\
\hline \multirow[t]{2}{*}{ Norte } & & $-3.18 \mathrm{E}-01$ & $-1.90 \mathrm{E}-01$ & $-1.85 \mathrm{E}-01$ & $-3.07 \mathrm{E}-01$ & $-3.69 \mathrm{E}-01$ \\
\hline & & $2.96 \mathrm{E}-02 * * *$ & $2.92 \mathrm{E}-02 * * *$ & $2.92 \mathrm{E}-02 * * *$ & 3.03 E-02*** & 3.08E-02*** \\
\hline \multirow[t]{2}{*}{ Nordeste } & & $6.19 \mathrm{E}-02$ & $1.21 \mathrm{E}-01$ & $1.34 \mathrm{E}-01$ & $8.95 \mathrm{E}-02$ & $4.31 \mathrm{E}-02$ \\
\hline & & $2.87 \mathrm{E}-02 *$ & $2.87 \mathrm{E}-02 * * *$ & 2.89E-02*** & $2.85 \mathrm{E}-02^{* *}$ & $2.87 \mathrm{E}-02$ \\
\hline \multirow[t]{2}{*}{ Sul } & & $-6.80 \mathrm{E}-03$ & $-3.88 \mathrm{E}-02$ & $-4.20 \mathrm{E}-02$ & $1.07 \mathrm{E}-01$ & $1.11 \mathrm{E}-01$ \\
\hline & & $1.68 \mathrm{E}-02$ & $1.69 \mathrm{E}-02 *$ & $1.70 \mathrm{E}-02 *$ & $1.87 \mathrm{E}-02 * * *$ & $1.86 \mathrm{E}-02^{* * *}$ \\
\hline \multirow[t]{2}{*}{ Centro-oeste } & & $-2.42 \mathrm{E}-01$ & $-2.53 \mathrm{E}-01$ & $-2.43 \mathrm{E}-01$ & $-3.19 \mathrm{E}-01$ & $-2.98 \mathrm{E}-01$ \\
\hline & & 2.29E-02*** & $2.32 \mathrm{E}-02 * * *$ & $2.36 \mathrm{E}-02 * * *$ & $2.38 \mathrm{E}-02 * * *$ & $2.38 \mathrm{E}-02 * * *$ \\
\hline \multirow[t]{2}{*}{ educ_2000 } & & & & $-3.20 \mathrm{E}-02$ & $-3.05 \mathrm{E}-02$ & $-9.13 \mathrm{E}-03$ \\
\hline & & & & $8.45 \mathrm{E}-03 * * *$ & 8.27E-03*** & $8.54 \mathrm{E}-03$ \\
\hline \multirow[t]{2}{*}{ Pent } & & & & & $-6.52 \mathrm{E}-03$ & $-6.98 \mathrm{E}-03$ \\
\hline & & & & & $1.25 \mathrm{E}-03 * * *$ & 1.25E-03*** \\
\hline \multirow[t]{2}{*}{ Nonwhite } & & & & & $8.95 \mathrm{E}-03$ & $8.03 \mathrm{E}-03$ \\
\hline & & & & & $4.63 \mathrm{E}-04^{* * * *}$ & 4.71E-04*** \\
\hline \multirow[t]{2}{*}{ ExtPob2000 } & $3.34 \mathrm{E}-03$ & $3.31 \mathrm{E}-03$ & $5.13 \mathrm{E}-03$ & $4.91 \mathrm{E}-03$ & $3.65 \mathrm{E}-03$ & 0.0026545 \\
\hline & $5.73 \mathrm{E}-04 * * *$ & $6.05 \mathrm{E}-04 * * * *$ & $6.02 \mathrm{E}-04 * * *$ & $6.06 \mathrm{E}-04 * * *$ & $5.94 \mathrm{E}-04^{* * * *}$ & $6.01 \mathrm{E}-04 * * *$ \\
\hline \multirow[t]{2}{*}{ ExtPob2010 } & $9.33 \mathrm{E}-05$ & $3.54 \mathrm{E}-04$ & $5.52 \mathrm{E}-04$ & $5.78 \mathrm{E}-04$ & $3.47 \mathrm{E}-04$ & $2.16 \mathrm{E}-04$ \\
\hline & $2.56 \mathrm{E}-04$ & 2.49E-04 & $2.55 \mathrm{E}-04^{*}$ & $2.55 \mathrm{E}-04^{*}$ & $2.47 \mathrm{E}-04$ & $2.44 \mathrm{E}-04$ \\
\hline \multirow[t]{2}{*}{ Constant } & $-4.21 \mathrm{E}-01$ & $-3.89 \mathrm{E}-01$ & $-3.29 \mathrm{E}-01$ & $-1.26 \mathrm{E}-01$ & $-2.80 \mathrm{E}-01$ & $-4.22 \mathrm{E}-01$ \\
\hline & $1.65 \mathrm{E}-02 * * *$ & $2.00 \mathrm{E}-02 * * *$ & $1.95 \mathrm{E}-02 * * *$ & $5.28 \mathrm{E}-02 *$ & $5.29 \mathrm{E}-02 * * *$ & $5.49 \mathrm{E}-02 * * *$ \\
\hline \multirow{4}{*}{$\begin{array}{l}\text { Obs } \\
\text { Pseudo-R² } \\
\text { (phi) }\end{array}$} & 5564 & 5564 & 5564 & 5507 & 5471 & 5471 \\
\hline & 0.5159 & 0.5514 & 0.5393 & 0.5401 & 0.5672 & 0.5744 \\
\hline & 18.9093 & 20.4286 & 19.9098 & 19.9125 & 21.3123 & 21.6261 \\
\hline & $0.3503^{* * * *}$ & $0.3791 * * *$ & $0.3692 * * *$ & $0.3712^{* * *}$ & $0.3992 * * *$ & $0.4052^{* * * *}$ \\
\hline
\end{tabular}

Nota: A notação para a significância estatística em todas as tabelas é: *** significativo ao nível de $0,1 \%$; ** significativo ao nível de $1 \% ;$ * significativo ao nível de $5 \%$. 
Os resultados apresentados na Tabela 5 mostram que os coeficientes estimados são, em geral, de magnitudes próximas, apesar de levemente inferiores aos apresentados na Tabela 3, bem como similares em significância estatística. Para as variáveis que capturam o efeito do PBF sobre a votação de Dilma, o coeficiente da variável BFpercap foi estatisticamente não significativo somente na especificação apresentada na coluna 6. Assim, os resultados indicam que a proporção de votos em Dilma foi influenciada pelo alcance e magnitude do programa, como constatado anteriormente. Para as demais variáveis, também se observam magnitudes e níveis de significância similares àqueles apresentados na Tabela 3.

É interessante destacar ainda que: a) os coeficientes estimados para a variável que captura a incidência de pobreza em 2000 (ExtPob2000) são positivos, mas nem sempre significativos; e b) os coeficientes obtidos da variável que captura a prevalência da pobreza em 2010 (ExtPob2010) são positivos, apesar de só mostrarem significância estatística nas colunas 3 e 4. Isso revela a suspeita inicial de que, em municípios mais pobres, o PT alcança maior votação, independentemente do alcance e montante recebido pelos cidadãos através do PBF. Além disso, ajuda a explicar porque as estimativas dos coeficientes associados às variáveis do PBF têm menor magnitude do que os obtidos nos modelos sem controle de pobreza, ou seja, do viés por variáveis omitidas, embora seja pequeno.

Quando se inclui, entre o conjunto de controles, a renda domiciliar per capita média dos municípios, com os resultados apresentados na Tabela 6 , os resultados obtidos seguem indicando que o PBF exerceu significativa influência sobre a proporção de votos realizados em Dilma no segundo turno das eleições presidenciais de 2010. Em todas as especificações, os coeficientes das duas variáveis que capturam os efeitos do PBF são significativos. Percebe-se, apenas, que suas magnitudes são ligeiramente inferiores em relação àquelas apresentadas nas Tabelas 3 e 5. 
Tabela 6 - Resultados das regressões beta com controles de extrema pobreza em 2000 e 2010 e renda per capita domiciliar em 2010

\begin{tabular}{|c|c|c|c|c|c|c|}
\hline \multicolumn{7}{|c|}{ Variável dependente: proporção de votos em Dilma no segundo turno de 2010 (Dilma 2010.2) } \\
\hline & (1) & $(2)$ & (3) & (4) & $(5)$ & $(6)$ \\
\hline \multirow[t]{2}{*}{ alcance_BF } & 2.05 & 2.02 & & & & 1.33 \\
\hline & $7.32 \mathrm{E}-02 * * *$ & $8.21 \mathrm{E}-02 * * *$ & & & & $1.62 \mathrm{E}-01 * * *$ \\
\hline \multirow[t]{2}{*}{ BFpercap } & & & $7.65 \mathrm{E}-03$ & $7.58 \mathrm{E}-03$ & $5.71 \mathrm{E}-03$ & $1.15 \mathrm{E}-03$ \\
\hline & & & $3.52 \mathrm{E}-04 * * *$ & $3.67 \mathrm{E}-04 * * *$ & $3.73 \mathrm{E}-04 * * *$ & 6.72E-04. \\
\hline \multirow[t]{2}{*}{ crescpibpc2006_ } & $-2.17 \mathrm{E}-11$ & $-2.28 \mathrm{E}-11$ & $-2.04 \mathrm{E}-11$ & & & \\
\hline & $3.70 \mathrm{E}-11$ & $3.57 \mathrm{E}-11$ & $3.62 \mathrm{E}-11$ & & & \\
\hline \multirow[t]{2}{*}{ pibpercap2008 } & $1.01 \mathrm{E}-06$ & $1.45 \mathrm{E}-06$ & $1.61 \mathrm{E}-06$ & & & \\
\hline & $6.00 \mathrm{E}-06$ & $5.82 \mathrm{E}-07 *$ & $5.86 \mathrm{E}-07 * *$ & & & \\
\hline \multirow[t]{2}{*}{ govpt 2006} & & $-1.75 \mathrm{E}-01$ & $-1.78 \mathrm{E}-01$ & $-1.81 \mathrm{E}-01$ & $-2.51 \mathrm{E}-01$ & $-2.22 \mathrm{E}-01$ \\
\hline & & $2.06 \mathrm{E}-02 * * *$ & $2.18 \mathrm{E}-02 * * *$ & $2.19 \mathrm{E}-02 * * *$ & $2.17 \mathrm{E}-02 * * *$ & $2.18 \mathrm{E}-02^{* * *}$ \\
\hline \multirow[t]{2}{*}{ pref_PT } & & $-4.15 \mathrm{E}-02$ & $9.04 \mathrm{E}-03$ & 4.75E-03 & $-2.12 \mathrm{E}-02$ & $-2.14 \mathrm{E}-02$ \\
\hline & & $1.99 \mathrm{E}-02^{*}$ & 2.27E-02 & $2.29 \mathrm{E}-02$ & 2.24E-02 & 2.22E-02 \\
\hline \multirow[t]{2}{*}{ prefgovpt } & & & $-2.49 \mathrm{E}-01$ & $-2.40 \mathrm{E}-01$ & $-2.26 \mathrm{E}-01$ & $-2.14 \mathrm{E}-01$ \\
\hline & & & $4.87 \mathrm{E}-02 * * *$ & $4.88 \mathrm{E}-02 * * *$ & $4.74 \mathrm{E}-02 * * *$ & $4.72 \mathrm{E}-02 * * *$ \\
\hline \multirow[t]{2}{*}{ Norte } & & $-3.17 \mathrm{E}-01$ & $-2.14 \mathrm{E}-01$ & $-2.13 \mathrm{E}-01$ & $-3.24 \mathrm{E}-01$ & $-3.77 \mathrm{E}-01$ \\
\hline & & $3.02 \mathrm{E}-02 * * *$ & $2.96 \mathrm{E}-02 * * *$ & 2.97E-02**** & $3.08 \mathrm{E}-02 * * *$ & $3.12 \mathrm{E}-02 * * *$ \\
\hline \multirow[t]{2}{*}{ Nordeste } & & $7.58 \mathrm{E}-02$ & $1.34 \mathrm{E}-01$ & $1.35 \mathrm{E}-01$ & $8.48 \mathrm{E}-02$ & 4.22E-02 \\
\hline & & $2.90 \mathrm{E}-02 * *$ & $2.88 \mathrm{E}-02^{* * * *}$ & $2.90 \mathrm{E}-02 * * *$ & $2.86 \mathrm{E}-02 * *$ & $2.89 \mathrm{E}-02$ \\
\hline \multirow[t]{2}{*}{ Sul } & & $3.37 \mathrm{E}-03$ & $-1.43 \mathrm{E}-02$ & $-1.49 \mathrm{E}-02$ & $1.14 \mathrm{E}-01$ & $1.15 \mathrm{E}-01$ \\
\hline & & $1.70 \mathrm{E}-02$ & $1.71 \mathrm{E}-02$ & $1.75 \mathrm{E}-02$ & $1.89 \mathrm{E}-02 * * *$ & $1.88 \mathrm{E}-02^{* * *}$ \\
\hline \multirow{2}{*}{ centroeste } & & $-2.37 \mathrm{E}-01$ & $-2.43 \mathrm{E}-01$ & $-2.29 \mathrm{E}-01$ & $-3.11 \mathrm{E}-01$ & $-2.95 \mathrm{E}-01$ \\
\hline & & $2.29 \mathrm{E}-02^{* * * *}$ & $2.32 \mathrm{E}-02^{* * * *}$ & $2.37 \mathrm{E}-02^{* * * *}$ & $2.42 \mathrm{E}-02 * * *$ & $2.41 \mathrm{E}-02^{* * * *}$ \\
\hline \multirow[t]{2}{*}{ educ_2000 } & & & & $2.01 \mathrm{E}-03$ & $-1.61 \mathrm{E}-02$ & $-2.27 \mathrm{E}-03$ \\
\hline & & & & $1.02 \mathrm{E}-02$ & $1.02 \mathrm{E}-02$ & $1.02 \mathrm{E}-02$ \\
\hline \multirow[t]{2}{*}{ Pent } & & & & & $-6.73 \mathrm{E}-03$ & $-7.07 \mathrm{E}-03$ \\
\hline & & & & & $1.25 \mathrm{E}-03 * * *$ & $1.25 \mathrm{E}-02 * * *$ \\
\hline \multirow[t]{2}{*}{ nonwhite } & & & & & $8.71 \mathrm{E}-03$ & $7.94 \mathrm{E}-03$ \\
\hline & & & & & $4.71 \mathrm{E}-02 * * *$ & $4.77 \mathrm{E}-02 * * *$ \\
\hline \multirow[t]{2}{*}{ ExtPob2000 } & $4.74 \mathrm{E}-03$ & $2.25 \mathrm{E}-03$ & $2.34 \mathrm{E}-03$ & $2.34 \mathrm{E}-03$ & $1.28 \mathrm{E}-03$ & $1.22 \mathrm{E}-03$ \\
\hline & $9.18 \mathrm{E}-04 * * *$ & $9.09 \mathrm{E}-04 *$ & $9.16 \mathrm{E}-04 *$ & $9.21 \mathrm{E}-04 *$ & $9.01 \mathrm{E}-04$ & $8.96 \mathrm{E}-04$ \\
\hline \multirow[t]{2}{*}{ ExtPob2010 } & $-2.30 \mathrm{E}-03$ & $2.36 \mathrm{E}-03$ & $5.16 \mathrm{E}-03$ & $5.20 \mathrm{E}-03$ & $4.74 \mathrm{E}-03$ & $2.98 \mathrm{E}-03$ \\
\hline & $1.34 \mathrm{E}-03$. & $1.33 \mathrm{E}-03$. & $1.33 \mathrm{E}-03 * * *$ & $1.34 \mathrm{E}-03 * * *$ & $1.30 \mathrm{E}-03 * * *$ & $1.31 \mathrm{E}-03 *$ \\
\hline \multirow[t]{2}{*}{ Rdom_2010 } & $-1.44 \mathrm{E}-04$ & $-1.93 \mathrm{E}-04$ & $-3.49 \mathrm{E}-04$ & $-3.36 \mathrm{E}-04$ & $-1.29 \mathrm{E}-04$ & $-7.02 \mathrm{E}-05$ \\
\hline & 5.19E-05** & $5.11 \mathrm{E}-05^{* * * *}$ & $5.00 \mathrm{E}-05^{* * *}$ & $5.96 \mathrm{E}-05^{* * * *}$ & $5.95 \mathrm{E}-05^{*}$ & $5.95 \mathrm{E}-05$ \\
\hline \multirow[t]{2}{*}{ Constant } & $-3.11 \mathrm{E}-01$ & $-2.28 \mathrm{E}-01$ & $-5.00 \mathrm{E}-02$ & $-4.49 \mathrm{E}-02$ & $-2.45 \mathrm{E}-01$ & $-3.95 \mathrm{E}-01$ \\
\hline & $4.55 \mathrm{E}-02 * * *$ & $4.58 \mathrm{E}-02 * * *$ & 4.34E-02 & $5.47 \mathrm{E}-02$ & $5.54 \mathrm{E}-02 * * *$ & $5.79 \mathrm{E}-02 * * *$ \\
\hline Obs & 5563 & 5563 & 5563 & 5506 & 5470 & 5470 \\
\hline \multirow{3}{*}{$\begin{array}{l}\text { Pseudo- } R^{2} \\
\text { (phi) }\end{array}$} & 0.5166 & 0.5528 & 0.5446 & 0.5441 & 0.569 & 0.5751 \\
\hline & 18.9407 & 20.4822 & 20.1306 & 20.0671 & 21.3721 & 21.6447 \\
\hline & $0.3509 * * *$ & $0.3801 * * *$ & $0.3735 * * *$ & $0.3742 * * *$ & $0.4004 * * *$ & $0.4056 * * *$ \\
\hline
\end{tabular}

Notas: A notação para a significância estatística em todas as tabelas é: *** significativo ao nível de $0,1 \%$; * significativo ao nível de $1 \%$; * significativo ao nível de $5 \%$.

Destaca-se, ainda, que para as demais variáveis de controle, as estimações apresentadas na Tabela 6 mostram padrões similares aos já observados nas Tabelas 3 e 5. Novamente, a variável ExtPob2010 é positivamente correlacionada com a proporção de votos na candidata da situação. Além disso, o fato de que os coeficientes estimados da variável renda domiciliar per capita, na maior parte das especificações, serem negativos e significativos reforça a hipótese de que em regiões mais pobres o PT consegue obter maior proporção de votos. 
Por fim, as estimativas apresentadas na Tabela 7 reforçam a validade dos resultados obtidos anteriormente em relação à importância do efeito Lula e do bolsa família. Mesmo controlando por prevalência e incidência de pobreza, os coeficientes obtidos para o efeito Lula são bem próximos aos apresentados na Tabela 4. O mesmo pode ser dito para os coeficientes das variáveis que capturam o efeito do PBF.

Tabela 7 - Resultados das regressões beta com efeito Lula e controles para pobreza extrema em 2000 e 2010

\begin{tabular}{|c|c|c|c|c|c|c|}
\hline \multicolumn{7}{|c|}{ Variável dependente: proporção de votos em Dilma no segundo turno de 2010 (Dilma 2010.2) } \\
\hline & 7 & 8 & 9 & 10 & 11 & 12 \\
\hline \multirow[t]{2}{*}{ lula_vs_2006_2 } & 3.37 & & & 3.13 & 3.13 & 3.12 \\
\hline & $3.37 \mathrm{E}-02 * * *$ & & & $3.79 \mathrm{E}-02 * * *$ & $3.82 \mathrm{E}-02 * * *$ & $3.88 \mathrm{E}-02 * * *$ \\
\hline \multirow[t]{2}{*}{ alcance_BF } & & & & & & $1.89 \mathrm{E}-01$ \\
\hline & & & & & & $1.07 \mathrm{E}-01$. \\
\hline \multirow[t]{2}{*}{ BFpercap } & & $9.47 \mathrm{E}-03$ & $8.93 \mathrm{E}-03$ & $1.08 \mathrm{E}-03$ & $1.08 \mathrm{E}-03$ & $3.685 \mathrm{E}-04$ \\
\hline & & $3.01 \mathrm{E}-04 * * *$ & $3.08 \mathrm{E}-04 * * *$ & $2.28 \mathrm{E}-04 * * *$ & $2.30 \mathrm{E}-04 * * *$ & $4.670 \mathrm{E}-04$ \\
\hline \multirow[t]{2}{*}{ educ_2000 } & & $-1.45 \mathrm{E}-02$ & $-3.91 \mathrm{E}-02$ & $-5.13 \mathrm{E}-02$ & $-5.15 \mathrm{E}-02$ & $-4.856 \mathrm{E}-02$ \\
\hline & & $8.56 \mathrm{E}-03$. & $9.15 \mathrm{E}-03 * * *$ & $5.87 \mathrm{E}-03 * * *$ & $6.26 \mathrm{E}-03 * * *$ & $6.46 \mathrm{E}-03 * * *$ \\
\hline \multirow[t]{2}{*}{ IDH2000 } & $-1.44 \mathrm{E}-07$ & & & & & \\
\hline & $3.32 \mathrm{E}-08 * * *$ & & & & & \\
\hline \multirow[t]{2}{*}{ pref_PT } & & $-2.20 \mathrm{E}-03$ & $-8.30 \mathrm{E}-03$ & $-8.03 \mathrm{E}-02$ & $-8.04 \mathrm{E}-02$ & $-8.012 \mathrm{E}-02$ \\
\hline & & $2.34 \mathrm{E}-02$ & $2.33 \mathrm{E}-02$ & $1.59 \mathrm{E}-02 * * *$ & $1.59 \mathrm{E}-02 * * *$ & $1.59 \mathrm{E}-02 * * *$ \\
\hline \multirow[t]{2}{*}{ govpt 2006} & & $-1.56 \mathrm{E}-01$ & $-1.67 \mathrm{E}-01$ & $-3.75 \mathrm{E}-02$ & $-3.76 \mathrm{E}-02$ & $-3.705 \mathrm{E}-02$ \\
\hline & & $2.12 \mathrm{E}-02 * * *$ & $2.12 \mathrm{E}-02 * * *$ & $1.45 \mathrm{E}-02 * *$ & $1.46 \mathrm{E}-02 *$ & $1.46 \mathrm{E}-02 *$ \\
\hline \multirow[t]{2}{*}{ prefgovpt } & & $-2.49 \mathrm{E}-01$ & $-2.44 \mathrm{E}-01$ & $-1.67 \mathrm{E}-01$ & $-1.67 \mathrm{E}-01$ & $-1.666 \mathrm{E}-01$ \\
\hline & & $4.97 \mathrm{E}-02 * * *$ & $4.94 \mathrm{E}-02 * * *$ & $3.37 \mathrm{E}-02 * * *$ & $3.37 \mathrm{E}-02 * * *$ & $3.37 \mathrm{E}-02 * * *$ \\
\hline \multirow[t]{2}{*}{ Pent } & & $-1.10 \mathrm{E}-02$ & $-1.14 \mathrm{E}-02$ & $-9.10 \mathrm{E}-03$ & $-9.11 \mathrm{E}-03$ & $-9.309 \mathrm{E}-03$ \\
\hline & & $1.15 \mathrm{E}-03 * * *$ & $1.15 \mathrm{E}-03 * * *$ & $7.84 \mathrm{E}-04 * * *$ & $7.85 \mathrm{E}-04 * * *$ & $7.93 \mathrm{E}-04 * * *$ \\
\hline \multirow[t]{2}{*}{ Bfgini } & & & $1.82 \mathrm{E}-08$ & & $1.01 \mathrm{E}-10$ & $-3.959 \mathrm{E}-13$ \\
\hline & & & $2.48 \mathrm{E}-09 * * *$ & & $1.58 \mathrm{E}-09$ & $1.57 \mathrm{E}-09$ \\
\hline \multirow[t]{2}{*}{ ExtPob2000 } & $3.01 \mathrm{E}-04$ & $5.72 \mathrm{E}-03$ & $5.41 \mathrm{E}-03$ & $-1.91 \mathrm{E}-04$ & $-1.92 \mathrm{E}-04$ & $-4.169 \mathrm{E}-04$ \\
\hline & $6.46 \mathrm{E}-04$ & $5.53 \mathrm{E}-04 * * *$ & $5.53 \mathrm{E}-04 * * *$ & $3.83 \mathrm{E}-04$ & $3.84 \mathrm{E}-04$ & $4.035 \mathrm{E}-04$ \\
\hline \multirow[t]{2}{*}{ ExtPob2010 } & $4.06 \mathrm{E}-03$ & $3.64 \mathrm{E}-04$ & $8.32 \mathrm{E}-05$ & $1.66 \mathrm{E}-04$ & $1.65 \mathrm{E}-04$ & $1.44 \mathrm{E}-04$ \\
\hline & $9.28 \mathrm{E}-04 * * *$ & $2.58 \mathrm{E}-04$ & $2.60 \mathrm{E}-04$ & $1.73 \mathrm{E}-04$ & $1.75 \mathrm{E}-04$ & $1.745 \mathrm{E}-04$ \\
\hline \multirow[t]{2}{*}{ Constant } & -1.72 & -2.05 & -6.95 & -1.30 & -1.30 & -1.31 \\
\hline & $1.81 \mathrm{E}-02 * * *$ & $5.20 \mathrm{E}-02 * * *$ & $5.49 \mathrm{E}-02$ & $3.80 \mathrm{E}-02 * * *$ & $4.05 \mathrm{E}-02 * * *$ & $4.11 \mathrm{E}-02 * * *$ \\
\hline Obs & 5507 & 5473 & 5473 & 5473 & 5473 & 5473 \\
\hline \multirow{3}{*}{$\begin{array}{l}\text { Pseudo- } \mathrm{R}^{2} \\
\text { (phi) }\end{array}$} & 0.7708 & 0.5250 & 0.5292 & 0.7900 & 0.7900 & 0.7904 \\
\hline & 40.0473 & 19.2316 & 19.4250 & 44.0938 & 44.0938 & 44.1191 \\
\hline & $0.7549 * * *$ & $0.3593 * * *$ & $0.363 * * *$ & $0.8346 * * *$ & $0.8346 * * *$ & $0.835 * * *$ \\
\hline
\end{tabular}

Notas: A notação para a significância estatística em todas as tabelas é: *** significativo ao nível de $0,1 \% ;$ ** significativo ao nível de $1 \% ;$ * significativo ao nível de $5 \%$.

Em síntese, os resultados apresentados nas Tabelas de 5 a 7 mostram a robustez dos resultados obtidos anteriormente sobre a importância do PBF na proporção de votos obtidos pela candidata da situação. Os coeficientes estimados das variáveis que capturam o efeito do programa, sendo medido tanto pelo alcance do programa, quanto pelo seu valor per capita municipal, são muito próximos nas diferentes especificações. O mesmo pode ser dito das demais variáveis dos modelos e daquela que captura o efeito Lula. 


\section{Considerações Finais}

No presente artigo buscou-se investigar: a) se a cobertura do PBF e o crescimento do PIB per capita municipal foram relevantes para explicar a proporção de votos recebidos pela presidente Dilma Rousseff nos municípios brasileiros em 2010; e b) se o padrão de votação nos candidatos do PT e do PSDB no segundo turno das eleições presidenciais de 2010 foi semelhante ao identificado pela literatura no segundo turno da reeleição de Lula, em 2006, no que diz respeito às características sociais e econômicas do eleitorado. Controlando para a escolaridade média, o PIB per capita, a proporção de não brancos, a prevalência e a incidência da pobreza, a proporção de evangélicos pentecostais e as dummies políticas e regionais, testou-se a relevância do alcance e do volume de recursos destinados ao PBF e do crescimento do PIB per capita municipal sobre a proporção de votos recebidos pela então candidata Dilma nos municípios do país.

A elevada significância dos coeficientes das variáveis de alcance e valor per capita de recursos destinados ao PBF e a magnitude dos seus coeficientes estimados, principalmente da variável alcance, aliada à alternância de sinal e insignificância estatística do crescimento do PIB per capita, parecem indicar que, de fato, o grande percentual de votos obtidos por Dilma em grande parte dos municípios brasileiros, sobretudo nos menos desenvolvidos, decorre mais da dependência da população em relação aos programas assistencialistas e do incumbent effect do que da percepção de melhora da situação econômica geral dos municípios.

O alcance do PBF - que vai de pouco mais de $0,1 \%$ das famílias, no município menos beneficiado pelo programa, a mais de $92 \%$ das famílias, no município mais beneficiado - aparentemente exerceu papel relevante na continuidade do PT no poder, conforme a literatura revisada indica, além das evidências deste trabalho para as eleições de 2010. O fato de o país ser ainda classificado como sendo de renda média com má distribuição de renda faz com que esse efeito seja mais intenso em relação a economias mais maduras. No entanto, a interação do índice de distribuição de renda com as variáveis que medem o bolsa família não se mostraram significativas em todos os casos.

Neste artigo mostra-se que, mesmo incluindo o percentual de votos obtidos por Lula em 2006, o PBF apresentou um efeito positivo e significativo sobre o percentual de votos em Dilma. Além disso, os resultados são robustos à introdução de uma série de variáveis que poderiam causar viés por variável omitida.

Para futuras pesquisas, seria importante analisar com mais detalhes a importância do efeito Lula devido à sua grande relevância e se tal padrão tende a se manter nas eleições seguintes, além de detalhar as interações existentes entre as variáveis utilizadas no presente estudo para explicar a proporção de votos nos candidatos da situação e da oposição. Por exemplo, poder-se-ia analisar a interação 
do incumbent effect com o nível médio de escolaridade de cada município ou com o alcance dos programas de transferência de renda. Outro ponto que merece um estudo mais detalhado seria identificar a razão dos efeitos negativos para as variáveis referentes aos prefeitos e governadores do PT.

\section{Referências}

ABENSUR, T. C.; CRIBARI-NETO, F.; MENEZES; T. A. Impactos do Programa Bolsa Família nos resultados das eleições presidenciais no Brasil em 2006. In: ENCONTRO NACIONAL DE ECONOMIA DA ANPEC, 35., 2007, Niterói, RJ. Anais... Niterói: ANPEC, 2007.

ANSOLABEHERE, S.; SNYDER, J. The incumbency advantage in U.S. elections: an analysis of State and Federal Offices, 1942-2000. Election Law Journal, v. 1, n. 3, p. 315-338, 2000.

. Using term limits to estimate incumbency advantage when officeholders retire strategically. Legislative Studies Quarterly, v. 29, n. 4, p. 487-515, 2004.

ANSOLABEHERE, S.; SNYDER, J.; STEWART, C. Old voters, new voters and the personal vote: using redistricting to measure incumbency advantage. American Journal of Political Science, v. 44, n. 1, p. 17-34, 2000.

BRASIL. Controladoria-Geral da União. Portal da Transparência. Disponível em: <www. portaltransparencia.gov.br>. Acesso em: 01 fev. 2012.

CANÊDO-PINHEIRO, M. Bolsa-Família ou desempenho da economia? Determinantes da reeleição de Lula em 2006. In: ENCONTRO NACIONAL DE ECONOMIA DA ANPEC, 37. 2009, Foz do Iguaçu, PR. Anais... Foz do Iguaçu, PR: ANPEC, 2009.

CERDA, R.; VERGARA, R. Government subsidies and presidential election outcomes: evidence for a developing country. World Development, v. 36, n. 11, p. 2470-88, 2008.

CRIBARI-NETO, F.; ZEILEIS, A. Beta Regression in R. Journal of Statistical Software, v. 34, n. 2, p. 1-24, 2010.

DE LA O, A. L. Do conditional cash transfers affect electoral behavior? Evidence from a randomized experiment in Mexico. American Journal of Political Science, v. 57, n. 1, p. 1-14, 2013.

ELLERY, R.; PAES DE BARROS, R.; GROSNER, D. Determinantes da produtividade do trabalho para a estratégia sobre sustentabilidade e promoção da classe média. Brasília, DF: Secretaria de Assuntos Estratégicos da Presidência da República, 2013.

FAIR, R. C. The effect of economic events on votes for president. The Review of Economics and Statistics, v. 60, n. 2, p. 159-173, 1978.

FERREIRA, A. L.; SAKURAI, S. N.; OLIVEIRA, R. Oito anos construindo popularidade. Revista Economia 8 Tecnologia, v. 7, n. especial, p. 5-15, 2011.

GRUEN, B.; KOSMIDIS, I.; ZEILEIS, A. Extended beta regression in R: Shaken, Stirred, Mixed, and Partitioned. Journal of Statistical Software, v. 48, n. 11, p. 1-25, 2012. 
HUNTER, W.; POWER, T. J. Rewarding Lula: Executive Power, Social Policy, and the Brazilian Elections of 2006. Latin American Politics and Society, v. 49, n. 1, p. 1-30, 2007.

KAHANE, L. H. It's the Economy, and then some: modeling the presidential vote with State Panel Data. Public Choice, v. 139, n. 3/4, p. 343-356, 2009.

LEVITT, S. D.; SNYDER JR., J. M. The impact of federal spending on house election outcomes. Journal of Political Economy, v. 105, n. 1, p. 30-53, Feb. 1997.

MANACORDA, M.; EDWARD, M.; VIGORITO, A. Government transfers and political support. Cambridge, MA: National Bureau of Economic Research, 2010. (Working Paper, n. 14702).

MARQUES, R. M. A Importância do Bolsa Família nos municípios brasileiros. Brasília, DF: Ministério do Desenvolvimento Social e Combate à Fome, 2005. (Cadernos de Estudo: Desenvolvimento Social em Debate, n. 1).

MARQUES, R. M. et al. Discutindo o papel do Programa Bolsa Família na decisão das eleições presidenciais brasileiras de 2006. Revista de Economia Política, v. 29, n.1, p. 114 $132,2009$.

NICOLAU, J.; PEIXOTO, V. Uma disputa em três tempos: uma análise das bases municipais das eleições presidenciais de 2006. In: ENCONTRO NACIONAL DA ANPOCS, 31., 2007, Caxambu, MG. Anais... Caxambu, MG: Anpocs, 2007.

PEREIRA, A. E.; NAKABASHI, L.; SHIKIDA, C. D. Análise introdutória dos determinantes da eleição de Dilma. Economia E Tecnologia, ano 7, v. 26, p. 99-108, 2011.

PROGRAMA DAS NAÇÕES UNIDAS PARA O DESENVOLVIMENTO. Atlas do Desenvolvimento Humano no Brasil. Disponível em: < http://www.atlasbrasil.org.br > . Acesso em: 01 fev. 2012.

R DEVELOPMENT CORE TEAM. R: a language and environment for statistical computing. Vienna, Austria: R Foundation for Statistical Computing, 2011. Disponível em: < http:// www.R-project.org > . Acesso em: 01 fev. 2012.

SHIKIDA, C. D. et al. It is the economy, companheiro! An empirical analysis of Lula's reelection. Economics Bulletin, v. 29, n. 2, p. 976-991, 2009.

UPPAL, Y. Estimating incumbency effects in U.S. State legislatures: a quasi-experimental study. Economics E Politics, v. 22, n. 2, p. 180-199, 2010.

UPPAL, Y. The disadvantaged incumbents: estimating incumbency effects in Indian state legislatures. Public Choice, v. 138, n. 9-27, 2009.

ZUCCO, C. The president's 'new' constituency: Lula and the pragmatic vote in Brazil's 2006 presidential elections. Journal of Latin American Studies, v. 40, n. 1, p. 29-39, 2008. 


\section{Apêndice A - Tabelas Adicionais}

Tabela 8 - Efeitos marginais referentes aos resultados da Tabela 3

\begin{tabular}{lllllll}
\hline & $(1)$ & $(2)$ & $(3)$ & $(4)$ & $(5)$ & $(6)$ \\
\hline alcanceBF & $5.74 \mathrm{E}-01$ & $5.61 \mathrm{E}-01$ & & & & $3.72 \mathrm{E}-01$ \\
BFpercap & & & $2.34 \mathrm{E}-03$ & $2.08 \mathrm{E}-03$ & $1.46 \mathrm{E}-03$ & $1.41 \mathrm{E}-04$ \\
crescPIB & $-3.66 \mathrm{E}-12$ & $-3.18 \mathrm{E}-12$ & $3.26 \mathrm{E}-13$ & & & \\
PIBpercap & $2.00 \mathrm{E}-07$ & $2.66 \mathrm{E}-07$ & $1.88 \mathrm{E}-07$ & & & \\
govPT & & $-4.17 \mathrm{E}-02$ & $-4.44 \mathrm{E}-02$ & $-4.58 \mathrm{E}-02$ & $-6.26 \mathrm{E}-02$ & $-5.37 \mathrm{E}-02$ \\
prefPT & & $-9.64 \mathrm{E}-03$ & $1.84 \mathrm{E}-03$ & $2.41 \mathrm{E}-03$ & $-4.70 \mathrm{E}-03$ & $-4.90 \mathrm{E}-03$ \\
pref*govPT & & & $-5.77 \mathrm{E}-02$ & $-5.76 \mathrm{E}-02$ & $-5.42 \mathrm{E}-02$ & $-5.11 \mathrm{E}-02$ \\
Norte & & $-6.49 \mathrm{E}-02$ & $-2.20 \mathrm{E}-02$ & $-2.18 \mathrm{E}-02$ & $-5.89 \mathrm{E}-02$ & $-8.10 \mathrm{E}-02$ \\
Nordeste & & $3.06 \mathrm{E}-02$ & $5.70 \mathrm{E}-02$ & $5.92 \mathrm{E}-02$ & $4.03 \mathrm{E}-02$ & $2.22 \mathrm{E}-02$ \\
Sul & & $-1.20 \mathrm{E}-03$ & $-9.39 \mathrm{E}-03$ & $-1.03 \mathrm{E}-02$ & $2.63 \mathrm{E}-02$ & $2.69 \mathrm{E}-02$ \\
Centro-Oeste & & $-5.72 \mathrm{E}-02$ & $-5.93 \mathrm{E}-02$ & $-5.71 \mathrm{E}-02$ & $-7.59 \mathrm{E}-02$ & $-7.05 \mathrm{E}-02$ \\
Educ & & & & $-9.10 \mathrm{E}-03$ & $-8.25 \mathrm{E}-03$ & $-2.27 \mathrm{E}-03$ \\
Pentecost & & & & $-1.74 \mathrm{E}-03$ & $-1.81 \mathrm{E}-03$ \\
Nbranco & & & & & $2.22 \mathrm{E}-03$ & 0.00195017 \\
\hline
\end{tabular}

Fonte: Elaboração própria.

Tabela 9 - Efeitos marginais referentes aos resultados da Tabela 4

\begin{tabular}{lllllll}
\hline & $(7)$ & $(8)$ & $(9)$ & $(10)$ & $(11)$ & $(12)$ \\
\hline $\begin{array}{l}\text { Lula2006,2 } \\
\text { Alcance BF }\end{array}$ & $8.48 \mathrm{E}-01$ & & & $7.48 \mathrm{E}-01$ & $7.48 \mathrm{E}-01$ & $7.45 \mathrm{E}-01$ \\
BFpercap & & $2.62 \mathrm{E}-03$ & $2.62 \mathrm{E}-03$ & $2.55 \mathrm{E}-04$ & $2.54 \mathrm{E}-04$ & $5.79 \mathrm{E}-02$ \\
Educ & & $-4.05 \mathrm{E}-03$ & $-4.05 \mathrm{E}-03$ & $-1.22 \mathrm{E}-02$ & $-1.23 \mathrm{E}-02$ & $-1.17 \mathrm{E}-02$ \\
Idh & $-6.42 \mathrm{E}-10$ & & & & & \\
prefPT & & $-1.21 \mathrm{E}-03$ & $-1.21 \mathrm{E}-03$ & $-1.93 \mathrm{E}-02$ & $-1.93 \mathrm{E}-02$ & $-1.93 \mathrm{E}-02$ \\
govPT & & $-3.10 \mathrm{E}-02$ & $-3.10 \mathrm{E}-02$ & $-9.02 \mathrm{E}-03$ & $-9.08 \mathrm{E}-03$ & $-8.93 \mathrm{E}-03$ \\
pref*govPT & & $-5.71 \mathrm{E}-02$ & $-5.71 \mathrm{E}-02$ & $-4.06 \mathrm{E}-02$ & $-4.06 \mathrm{E}-02$ & $-4.06 \mathrm{E}-02$ \\
Pentecost & & $-2.90 \mathrm{E}-03$ & $-2.90 \mathrm{E}-03$ & $-2.17 \mathrm{E}-03$ & $-2.17 \mathrm{E}-03$ & $-2.22 \mathrm{E}-03$ \\
BF*gini & & & & & $6.22 \mathrm{E}-11$ & $1.30 \mathrm{E}-11$ \\
\hline
\end{tabular}

Fonte: Elaboração própria.

Tabela 10 - Efeitos marginais referentes aos resultados da Tabela 5

\begin{tabular}{lllllll}
\hline & $(1)$ & $(2)$ & $(3)$ & $(4)$ & $(5)$ & $(6)$ \\
\hline alcanceBF & $5.22 \mathrm{E}-01$ & $5.37 \mathrm{E}-01$ & & & & $3.35 \mathrm{E}-01$ \\
BFpercap & & & $2.22 \mathrm{E}-03$ & $2.00 \mathrm{E}-03$ & $1.42 \mathrm{E}-03$ & $2.42 \mathrm{E}-04$ \\
crescPIB & $-3.72 \mathrm{E}-12$ & $-3.73 \mathrm{E}-12$ & $-1.00 \mathrm{E}-12$ & & & \\
PIBpercap & $1.55 \mathrm{E}-07$ & $2.44 \mathrm{E}-07$ & $1.82 \mathrm{E}-07$ & & & \\
govPT & & $-4.11 \mathrm{E}-02$ & $-4.26 \mathrm{E}-02$ & $-4.39 \mathrm{E}-02$ & $-6.06 \mathrm{E}-02$ & $-5.32 \mathrm{E}-02$ \\
prefPT & & $-1.01 \mathrm{E}-02$ & $1.22 \mathrm{E}-03$ & $1.56 \mathrm{E}-03$ & $-5.01 \mathrm{E}-03$ & $-5.10 \mathrm{E}-03$ \\
pref*govPT & & & $-5.82 \mathrm{E}-02$ & $-5.79 \mathrm{E}-02$ & $-5.46 \mathrm{E}-02$ & $-5.17 \mathrm{E}-02$ \\
Norte & & $-7.77 \mathrm{E}-02$ & $-4.61 \mathrm{E}-02$ & $-4.50 \mathrm{E}-02$ & $-7.51 \mathrm{E}-02$ & $-9.04 \mathrm{E}-02$ \\
Nordeste & & $1.48 \mathrm{E}-02$ & $2.89 \mathrm{E}-02$ & $3.18 \mathrm{E}-02$ & $2.13 \mathrm{E}-02$ & $1.03 \mathrm{E}-02$ \\
Sul & & $-1.63 \mathrm{E}-03$ & $-9.31 \mathrm{E}-03$ & $-1.01 \mathrm{E}-02$ & $2.55 \mathrm{E}-02$ & $2.63 \mathrm{E}-02$ \\
Centro-Oeste & & $-5.78 \mathrm{E}-02$ & $-6.05 \mathrm{E}-02$ & $-5.81 \mathrm{E}-02$ & $-7.63 \mathrm{E}-02$ & $-7.13 \mathrm{E}-02$ \\
Educ & & & & $-7.65 \mathrm{E}-03$ & $-7.30 \mathrm{E}-03$ & $-2.18 \mathrm{E}-03$ \\
Pentecost & & & & $-1.56 \mathrm{E}-03$ & $-1.67 \mathrm{E}-03$ \\
Nbranco & & & & & $2.14 \mathrm{E}-03$ & $1.92 \mathrm{E}-03$ \\
ExtPob2000 & & & & & & \\
ExtPob2010 & & & & & & \\
\end{tabular}

Fonte: Elaboração própria. 
Tabela 11 - Efeitos marginais referentes aos resultados da Tabela 6

\begin{tabular}{lllllll}
\hline & 1 & 2 & 3 & 4 & 5 & 6 \\
\hline alcanceBF & $4.91 \mathrm{E}-01$ & $4.85 \mathrm{E}-01$ & & & & $3.18 \mathrm{E}-01$ \\
BFpercap & & & $1.83 \mathrm{E}-03$ & $1.82 \mathrm{E}-03$ & $1.36 \mathrm{E}-03$ & $2.75 \mathrm{E}-04$ \\
crescPIB & $-5.20 \mathrm{E}-12$ & $-5.47 \mathrm{E}-12$ & $-4.90 \mathrm{E}-12$ & & \\
PIBpercap & $2.41 \mathrm{E}-07$ & $3.48 \mathrm{E}-07$ & $3.85 \mathrm{E}-07$ & & & \\
govPT & & $-4.24 \mathrm{E}-02$ & $-4.32 \mathrm{E}-02$ & $-4.37 \mathrm{E}-02$ & $-6.08 \mathrm{E}-02$ & $-5.38 \mathrm{E}-02$ \\
prefPT & & $-9.96 \mathrm{E}-03$ & $2.16 \mathrm{E}-03$ & $1.14 \mathrm{E}-03$ & $-5.09 \mathrm{E}-03$ & $-5.13 \mathrm{E}-03$ \\
pref*govPT & & & $-6.09 \mathrm{E}-02$ & $-5.85 \mathrm{E}-02$ & $-5.50 \mathrm{E}-02$ & $-5.21 \mathrm{E}-02$ \\
Norte & & $-7.74 \mathrm{E}-02$ & $-5.20 \mathrm{E}-02$ & $-5.18 \mathrm{E}-02$ & $-7.93 \mathrm{E}-02$ & $-9.22 \mathrm{E}-02$ \\
Nordeste & & $1.81 \mathrm{E}-02$ & $3.20 \mathrm{E}-02$ & $3.20 \mathrm{E}-02$ & $2.02 \mathrm{E}-02$ & $1.01 \mathrm{E}-02$ \\
Sul & & $8.07 \mathrm{E}-04$ & $-3.42 \mathrm{E}-03$ & $-3.57 \mathrm{E}-03$ & $2.71 \mathrm{E}-02$ & $2.72 \mathrm{E}-02$ \\
Centro-Oeste & & $-5.78 \mathrm{E}-02$ & $-5.92 \mathrm{E}-02$ & $-5.56 \mathrm{E}-02$ & $-7.59 \mathrm{E}-02$ & $-7.19 \mathrm{E}-02$ \\
Educ & & & & $4.80 \mathrm{E}-04$ & $-3.85 \mathrm{E}-03$ & $-5.42 \mathrm{E}-04$ \\
Pentecost & & & & $-1.61 \mathrm{E}-03$ & $-1.69 \mathrm{E}-03$ \\
Nbranco & & & & $2.08 \mathrm{E}-03$ & $1.90 \mathrm{E}-03$ \\
ExtPob2000 & $1.13 \mathrm{E}-03$ & $5.38 \mathrm{E}-04$ & $5.59 \mathrm{E}-04$ & $5.59 \mathrm{E}-04$ & $3.06 \mathrm{E}-04$ & $2.93 \mathrm{E}-04$ \\
ExtPob2010 & $-5.50 \mathrm{E}-04$ & $5.66 \mathrm{E}-04$ & $1.24 \mathrm{E}-03$ & $1.24 \mathrm{E}-03$ & $1.13 \mathrm{E}-03$ & $7.13 \mathrm{E}-04$ \\
Rdom_2010 & $-3.44 \mathrm{E}-05$ & $-4.63 \mathrm{E}-05$ & $-8.37 \mathrm{E}-05$ & $-8.03 \mathrm{E}-05$ & $-3.08 \mathrm{E}-05$ & $-1.68 \mathrm{E}-05$ \\
\hline
\end{tabular}

Fonte: Elaboração própria.

Tabela 12 - Efeitos marginais referentes aos resultados da Tabela 7

\begin{tabular}{lllllll}
\hline & 7 & 8 & 9 & 10 & 11 & 12 \\
\hline $\begin{array}{l}\text { Lula2006.2 } \\
\text { Alcance BF }\end{array}$ & $8.06 \mathrm{E}-01$ & & & $7.48 \mathrm{E}-01$ & $7.48 \mathrm{E}-01$ & $7.45 \mathrm{E}-01$ \\
$\begin{array}{l}\text { BFpercap } \\
\text { Educ }\end{array}$ & & $2.26 \mathrm{E}-03$ & $2.14 \mathrm{E}-03$ & $2.58 \mathrm{E}-04$ & $2.58 \mathrm{E}-04$ & $8.52 \mathrm{E}-02$ \\
Idh & & $-3.47 \mathrm{E}-03$ & $-9.36 \mathrm{E}-03$ & $-1.23 \mathrm{E}-02$ & $-1.23 \mathrm{E}-02$ & $-1.16 \mathrm{E}-02$ \\
prefPT & $-3.44 \mathrm{E}-08$ & & & & & \\
govPT & & $-5.28 \mathrm{E}-04$ & $-4.04 \mathrm{E}-02$ & $-1.93 \mathrm{E}-02$ & $-1.93 \mathrm{E}-02$ & $-1.93 \mathrm{E}-02$ \\
pref*govPT & & $-3.77 \mathrm{E}-02$ & $-1.99 \mathrm{E}-03$ & $-8.98 \mathrm{E}-03$ & $-9.00 \mathrm{E}-03$ & $-8.87 \mathrm{E}-03$ \\
Pentecost & & $-6.07 \mathrm{E}-02$ & $-5.94 \mathrm{E}-02$ & $-4.06 \mathrm{E}-02$ & $-4.06 \mathrm{E}-02$ & $-4.04 \mathrm{E}-02$ \\
BF*gini & & $-2.63 \mathrm{E}-03$ & $-2.73 \mathrm{E}-03$ & $-2.17 \mathrm{E}-03$ & $-2.18 \mathrm{E}-03$ & $-2.22 \mathrm{E}-03$ \\
ExtPob2000 & $7.21 \mathrm{E}-05$ & $1.37 \mathrm{E}-03$ & $1.29 \mathrm{E}-03$ & $-4.55 \mathrm{E}-05$ & $-4.59 \mathrm{E}-05$ & $-8.95 \mathrm{E}-12$ \\
ExtPob2010 & $9.70 \mathrm{E}-04$ & $8.71 \mathrm{E}-05$ & $1.99 \mathrm{E}-05$ & $3.97 \mathrm{E}-05$ & $3.94 \mathrm{E}-05$ & $3.43 \mathrm{E}-05$ \\
\hline
\end{tabular}

Fonte: Elaboração própria.

Recebido em: 23/11/2013.

Aceito em: 19/08/2014. 